\title{
The Physiology and Pathophysiology of Pancreatic Ductal Secretion
}

\author{
The Background for Clinicians
}

\author{
Petra Pallagi, PhD, * Péter Hegyi, MD, PhD, DSc, *广 and Zoltán Rakonczay, Jr, MD, PhD, DSc*
}

\begin{abstract}
The human exocrine pancreas consists of 2 main cell types: acinar and ductal cells. These exocrine cells interact closely to contribute to the secretion of pancreatic juice. The most important ion in terms of the pancreatic ductal secretion is $\mathrm{HCO}_{3}^{-}$. In fact, duct cells produce an alkaline fluid that may contain up to $140 \mathrm{mM} \mathrm{NaHCO}-$, which is essential for normal digestion. This article provides an overview of the basics of pancreatic ductal physiology and pathophysiology. In the first part of the article, we discuss the ductal electrolyte and fluid transporters and their regulation. The central role of cystic fibrosis transmembrane conductance regulator (CFTR) is highlighted, which is much more than just a $\mathrm{Cl}^{-}$channel. We also review the role of pancreatic ducts in severe debilitating diseases such as cystic fibrosis (caused by various genetic defects of $c f t r$ ), pancreatitis, and diabetes mellitus. Stimulation of ductal secretion in cystic fibrosis and pancreatitis may have beneficial effects in their treatment.
\end{abstract}

Key Words: pancreas, ductal secretion, cystic fibrosis, CFTR, pancreatitis, diabetes mellitus

(Pancreas 2015;44: 1211-1233)

T he human exocrine pancreas consists of 2 main cell types: acinar and ductal cells. These exocrine cells interact closely to contribute to the secretion of pancreatic juice. ${ }^{1}$ Acinar cells (which make up $>80 \%$ of the pancreatic mass) secrete an isotonic, $\mathrm{NaCl}-$ and $\mathrm{H}^{+}$-rich fluid containing various digestive enzymes. ${ }^{2}$ The secreted $\mathrm{Cl}^{-}$is then exchanged to $\mathrm{HCO}_{3}^{-}$by duct cells to produce an alkaline fluid that may contain up to $140 \mathrm{mM} \mathrm{NaHCO}_{3}^{-}$, which is essential for normal digestion. ${ }^{3-5}$ Although volume-wise the ducts cells account for approximately only $5 \%$ of the pancreas, a large proportion of the secreted pancreatic fluid is due to the duct cells. Under stimulated conditions, duct cells secrete a large quantity of electrolytes, which is followed by fluid movement. Ductal $\mathrm{HCO}_{3}^{-}$concentration in guinea pig (which is a commonly used model animal to study pancreatic secretion) can be as high as in humans; however, rats or mice can secrete only 70 to $80 \mathrm{mM} \mathrm{HCO}_{3}^{-5,6}$ Although the exact mechanism of ductal $\mathrm{HCO}_{3}^{-}$and fluid secretion is only partially understood, it is evident that the differences in $\mathrm{HCO}_{3}^{-}$concentration of the various species are due to the different expression of apical

From the *First Department of Medicine, University of Szeged; and $\dagger$ Hungarian Academy of Sciences-University of Szeged Translational Gastroenterology Research Group, Szeged, Hungary.

Received for publication September 3, 2014; accepted March 2, 2015.

Reprints: Zoltán Rakonczay, MD, PhD, DSc, First Department of Medicine,

University of Szeged, PO Box 427, H-6701 Szeged, Hungary

(e-mail: rakonczay.zoltan@med.u-szeged.hu).

Our research is supported by Hungarian National Development Agency grants (TÁMOP-4.2.2.A-11/1/KONV-2012-0035, TÁMOP-4.2.2-A-11/1/KONV2012-0052, TÁMOP-4.2.2.A-11/1/KONV-2012-0073), the Hungarian Scientific Research Fund (NF105758), the Hungarian Academy of Sciences (MTA-SZTE Momentum grant, LP2014-10/2014), and the European Union and the State of Hungary, cofinanced by the European Social Fund in the framework of TAMOP 4.2.4.A/2-11-1-2012-0001 National Excellence Program.

The authors declare no conflict of interest.

Copyright (C) 2015 Wolters Kluwer Health, Inc. All rights reserved. and basolateral transporters involved in the secretory process. In all cases, the physiological function of this alkaline fluid is to neutralize the acidic content secreted by acinar cells, to provide an optimal $\mathrm{pH}$ for digestive enzymes, to flush down digestive enzyme into the duodenum, and also to neutralize the gastric acid entering the duodenum. ${ }^{7}$ Importantly, $\mathrm{HCO}_{3}^{-}$has a crucial biochemical role in the physiological $\mathrm{pH}$ buffering system and is a chaotropic agent that prevents the denaturing of proteins such as digestive enzymes and mucins so it facilitates their solubilization in biological fluid. ${ }^{4,8}$

Investigating the mechanisms of pancreatic ductal $\mathrm{HCO}_{3}^{-}$ and fluid secretion also helps us to better understand pancreatic diseases. $^{4}$ Impaired ductal secretion can result in pancreatic damage, as seen in cystic fibrosis (CF), ${ }^{3,9}$ and may contribute to the development of other diseases such as acute and chronic pancreatitis. ${ }^{10}$

The aim of this review is to summarize the physiology and pathophysiology of pancreatic ductal epithelial cells (PDECs). We will try to keep things simple and not go into too much molecular detail. These have been discussed in recent reviews by distinguished experts in the field such as Argent et al, ${ }^{11}$ Ishiguro et $\mathrm{al},{ }^{3}$ Lee et al, ${ }^{6}$ group of Muallem, ${ }^{12}$ and Novak et al. ${ }^{13}$ With respect to ductal pathophysiology, only CF, pancreatitis, and diabetes mellitus are discussed, and we will not deal with pancreatic adenocarcinoma (mainly arising from ductal cells).

\section{MECHANISM OF PANCREATIC DUCTAL SECRETION}

For a long time, it was believed that the main function of PDECs is to ensure mechanical frame for acinar cells. In 1986, Barry Argent and his colleagues ${ }^{14}$ have worked out a method that made it possible to isolate intact pancreatic ducts and PDECs. This was a landmark discovery, because until then, ductal function could be investigated only in intact animals. From then on, it was possible to separately study the function of duct cells, and numerous publications proved that PDECs are responsible not only for the formation of a mechanical frame for the acini, but also for the $\mathrm{HCO}_{3}^{-}$and fluid secretion of the pancreatic juice. ${ }^{3}$ The development of pancreatic ductal cell lines have also helped us in understanding the secretory process, but as these are mainly derived from adenocarcinomas, their function may be compromised.

Whereas acinar cells have a relatively uniform morphology, the structure of duct cells is much more diverse. Perhaps the most enigmatic cell type of the exocrine pancreas is the centroacinar cells, which are localized at the junction of the acini and are closely associated with the terminal ductal epithelium. ${ }^{15}$ Epithelia are cuboidal along the proximal small ducts and are columnar in the distal large ducts. ${ }^{16}$ Therefore, it is not surprising that proximal and distal duct cells also differ in their function. $\mathrm{HCO}_{3}^{-}$secretion is thought to occur primarily in the proximal part of the ducts. ${ }^{3}$

\section{The Model of Pancreatic Ductal $\mathrm{HCO}_{3}^{-}$Secretion}

The exact mechanism how the exocrine pancreas secretes a large amount of the alkaline fluid has long been an enigma. Note 
that the $\mathrm{HCO}_{3}^{-}$concentration of the pancreatic juice in the stimulated state is more than 5 times that found in the serum. Major milestones in understanding the mechanism of pancreatic $\mathrm{HCO}_{3}^{-}$ secretion include the discovery of the acidic pancreatic juice in patients with $\mathrm{CF},{ }^{17}$ the isolation of pancreatic ducts, ${ }^{14}$ and the molecular identification of several ion channels and transporters of PDECs, such as the $\mathrm{CF}$ transmembrane conductance regulator (CFTR), ${ }^{18}$ the $\mathrm{Na}^{+} / \mathrm{HCO}_{3}^{-}$cotransporter (NBCe1-B, also known as pNBC1), ${ }^{19}$ and the solute carrier family 26 (SLC26) transporters. ${ }^{20,21}$ Our knowledge has also expanded about how ductal secretion is regulated. ${ }^{6}$

Pancreatic ductal $\mathrm{HCO}_{3}^{-}$secretion is a complex process that can be broadly divided into 2 separate steps. The first step of $\mathrm{HCO}_{3}^{-}$secretion is the accumulation of $\mathrm{HCO}_{3}^{-}$inside the duct cell across the basolateral membrane. This can be achieved via a direct mechanism through $\mathrm{Na}^{+} / \mathrm{HCO}_{3}^{-}$cotransporters or indirectly via the passive diffusion of $\mathrm{CO}_{2}$ through the cell membrane and the conversion of $\mathrm{CO}_{2}$ to $\mathrm{HCO}_{3}^{-}$and $\mathrm{H}^{+}$mediated by carbonic anhydrase ${ }^{22}$ and backward transport of protons by $\mathrm{Na}^{+} / \mathrm{H}^{+}$exchangers (NHEs) and an $\mathrm{H}^{+}$-ATPase. ${ }^{3}$ The second step of $\mathrm{HCO}_{3}^{-}$secretion across the apical membrane of PDECs is thought to be mediated by anion channels and transporters such as CFTR and SLC26 anion exchangers ${ }^{3}$ (Fig. 1).

How these transporters act in concert to produce a high $\mathrm{HCO}_{3}^{-}$secretion in humans is controversial. One hypothesis is that $\mathrm{HCO}_{3}^{-}$is secreted via the electroneutral $\mathrm{Cl}^{-} / \mathrm{HCO}_{3}^{-}$exchanger until the luminal concentration reaches about $70 \mathrm{mM}$, after which the additional $\mathrm{HCO}_{3}^{-}$required to raise the luminal concentration to $140 \mathrm{mM}$ is transported by CFTR. ${ }^{5}$ Another hypothesis suggests that 2 electrogenic SLC26 anion exchangers with isoformspecific stoichiometry mediate $\mathrm{HCO}_{3}^{-}$secretion at different sites along the ductal tree, and CFTR functions to activate the exchangers and to provide the luminal $\mathrm{Cl}^{-}$required for anion exchange to occur. ${ }^{4,6,23}$

\section{Electrolyte and Fluid Transporters of Pancreatic Ductal Cells}

\section{Cystic Fibrosis Transmembrane Conductance Regulator}

Cystic fibrosis transmembrane conductance regulator, the most critical player in $\mathrm{HCO}_{3}^{-}$secretion, was discovered 25 years ago as the gene whose mutation is responsible for $\mathrm{CF}^{18,24,25} \mathrm{It}$ is a cAMP-activated $\mathrm{Cl}^{-}$channel found in the plasma membrane, is a member of the ATP-binding cassette transporter superfamily. ATP-binding cassette transporters utilize the energy of ATP binding and hydrolysis to carry out certain biological processes. ${ }^{26}$ In fact, ATP-binding cassette transporters have 2 distinct domains:

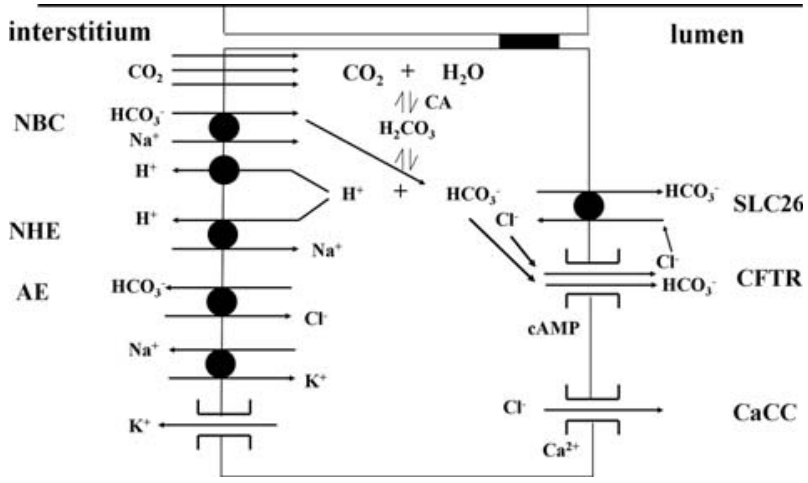

FIGURE 1. Schematic diagram of ion transport systems in pancreatic ductal epihelial cells. AE, anion exchanger. nucleotide-binding domains and transmembrane domains, which contain several membrane-spanning $\alpha$-helices and a regulatory (R) domain that is phosphorylated by protein kinase A and protein kinase $\mathrm{C}(\mathrm{PKC}) .^{27,28}$ In addition, CFTR contains several other domains mediating protein-protein interactions, including postsynaptic density 95/disc-large/zonula occludens 1 (PDZ)-interacting domains in the $\mathrm{C}$ terminus. Proteins that contain PDZ domains often have other protein-interacting modules (such as ezrin, radixin, moesin-binding domains, and coiled-coil domains) and therefore can promote homotypic and heterotypic protein-protein interactions. ${ }^{29}$

Cystic fibrosis transmembrane conductance regulator is found in the epithelial cells of many organs including the pancreas, lung, liver, digestive tract, reproductive tract, and skin. Although CFTR is predominantly a $\mathrm{Cl}^{-}$channel, it can also conduct other anions. Gray et $\mathrm{al}^{30}$ provided clear evidence that CFTR can transport $\mathrm{HCO}_{3}^{-}$in pancreatic duct cells, but CFTR is 3 to 5 times more selective for $\mathrm{Cl}^{-}$over $\mathrm{HCO}_{3}^{-} .{ }^{31}$ Interestingly, $\mathrm{Cl}^{-} / \mathrm{HCO}_{3}^{-}$selectivity of CFTR is dynamic and is regulated by external $\mathrm{Cl}^{-}{ }^{32}$ According to these studies, when $\mathrm{Cl}^{-}$is present in physiologic concentration in the lumen of proximal pancreatic ducts, CFTR functions as a $\mathrm{Cl}^{-}$channel and does not carry $\mathrm{HCO}_{3}^{-}$. However, when luminal $\left[\mathrm{Cl}^{-}\right]$and $\left[\mathrm{Cl}^{-}\right]_{\mathrm{i}}$ are low at the distal part of pancreatic ducts, CFTR secretes $\mathrm{HCO}_{3}^{-}$across the apical membrane of the ductal cells. ${ }^{33,34}$ It has been shown that $\mathrm{CFTR} \mathrm{Cl}^{-}$currents were rapidly inhibited by $\mathrm{HCO}_{3}^{-}$in a voltage-independent manner. ${ }^{35}$ Cystic fibrosis transmembrane conductance regulator $\mathrm{Cl}^{-}$permeability is switched by the WithNo-Lysine (WNK)/STE20/SPS1-related proline/alanine-rich kinase (SPAK) kinase pathway (which is regulated by $\left[\mathrm{Cl}^{-}\right]_{\mathrm{i}}$ ), making CFTR an $\mathrm{HCO}_{3}^{-}$-permeable channel. ${ }^{34,36}$ Inositol 1,4,5trisphosphate $\left(\mathrm{IP}_{3}\right)$ receptor $\left(\mathrm{IP}_{3} \mathrm{R}\right)$-binding protein released with $\mathrm{IP}_{3}$ (IRBIT), which is another recently described regulatory protein, also appears to play a fundemental role in the regulation of $\mathrm{HCO}_{3}^{-}$secretion. In addition, IRBIT seems to mediate synergism between intracellular $\mathrm{Ca}^{2+}$ and cAMP signaling. ${ }^{37}$

Another observation that highlighted the crucial role of CFTR in pancreatic $\mathrm{HCO}_{3}^{-}$secretion is that CFTR mutations associated with exocrine pancreatic insufficiency also show a major deficiency in the apical CFTR-dependent $\mathrm{Cl}^{-} / \mathrm{HCO}_{3}^{-}$exchange activity. ${ }^{38,39}$ In addition to acting as a $\mathrm{Cl}^{-}$channel, CFTR also directly or indirectly regulates several transport proteins via formation of macromolecular complexes. Functional interactions with CFTR were reported for the epithelial $\mathrm{Na}^{+}$ channel, $\mathrm{K}^{+}$channels, SLC26 anion exchangers, $\mathrm{Ca}^{2+}$ activated $\mathrm{Cl}^{-}$channel, $\mathrm{Na}^{+}-\mathrm{HCO}_{3}^{-}$transporters (NBCn1-A), NHEs, and aquaporin (AQP) water channels. ${ }^{4,28,40,41}$ Ko et al ${ }^{42}$ provided important evidence for the functional interaction between CFTR and select SLC26 transporters (SLC26A3, SLC26A4, and SLC26A6) and later localized the relevant interacting regions to the R domain of CFTR and the carboxyl terminus (sulfate transporter and anti-sigma factor antagonist [STAS] domain) of SLC26 transporters. $^{23}$ The interactions of CFTR and other transporters are mediated by protein-binding domains. In fact, the PDZ-interacting domain of human CFTR mediates its binding to several PDZ domain-containing proteins, including NHE regulatory factor isoform 1-4 (NHERF-1 to NHERF-4) and CFTR-associated ligands. ${ }^{43-45}$ It has also been demonstrated that the regulation of transporters by CFTR not only goes one way, but SLC26A6 can also modify CFTR activity in both the resting and stimulated states. ${ }^{46}$

\section{$\mathrm{Cl}^{-} / \mathrm{HCO}_{3}^{-}$Exchangers: Solute Carrier Families 4 and 26}

$\mathrm{Cl}^{-} / \mathrm{HCO}_{3}^{-}$exchangers are encoded by the SLC4 and SLC26 gene superfamilies and function to regulate intracellular $\mathrm{pH}$, 
$\left[\mathrm{Cl}^{-}\right]$, and cell volume. ${ }^{47}$ The SLC4 family includes 4 distinct Na-independent $\mathrm{Cl}^{-} / \mathrm{HCO}_{3}^{-}$exchangers known as AE1, AE2, AE3, and AE4, with AE1-3 exclusively located on the basolateral membrane of epithelial cells. ${ }^{48}$ Pancreatic duct cells express the housekeeping AE2 exchanger (SLC4A2) ${ }^{49,50}$ that mediates electroneural exchange of $1 \mathrm{Cl}^{-}$(into the cell) and $1 \mathrm{HCO}_{3}^{-}$ (from the cell to the interstitium). ${ }^{51}$ The activity of the latter transporter is likely to be inhibited during stimulated secretion (as it acts against it), which has been confirmed in guinea pig. ${ }^{51}$ The discovery of the SLC26 family of luminal $\mathrm{Cl}^{-} / \mathrm{HCO}_{3}^{-}$exchangers was a breakthrough in understanding the mechanism of pancreatic $\mathrm{HCO}_{3}^{-}$secretion. ${ }^{52}$ SLC26 isoforms are large, structurally well-conserved anion exchangers with highly restricted and distinct tissue distribution. The C-terminal cytoplasmic region of all SLC26 proteins includes a "sulfate transporter and anti-sigma factor antagonist (STAS) domain," which contains PDZ recognition motifs. ${ }^{53}$ To date, 10 SLC26 genes or isoforms (SLC26A1-SLC26A11) have been cloned (SLC26A10 is a pseudogene $){ }^{48}$ The family members have diverse substrate specificity. SLC26A1 and SLC26A2 were identified as $\mathrm{SO}_{4}^{2-}$ transporters, ${ }^{21}$ SLC26A3 and SLC26A6 function as $\mathrm{Cl}^{-} / \mathrm{HCO}_{3}^{-}$ exchangers. ${ }^{42,54} \mathrm{SLC} 26 \mathrm{~A} 4$ is an electroneutral $\mathrm{Cl}^{-} / \mathrm{HCO}_{3}^{-} / \mathrm{I}^{-}$ exchanger, ${ }^{55}$ SLC26A5 functions as an anion regulated, voltagedependent motor protein. ${ }^{56}$ SLC26A7, ${ }^{57}$ SLC26A9, ${ }^{58}$ and SLC26A1 $1^{59}$ are $\mathrm{Cl}^{-}$channels. ${ }^{6}$ The function of SLC26A8 is unclear, but it exhibits modest transport of $\mathrm{Cl}^{-}, \mathrm{SO}_{4}^{2-}$, and oxalate. ${ }^{60}$

In pancreatic ducts, the expression of SLC26A2, ${ }^{61}$ SLC26A3 ${ }^{62}$ SLC26A6, ${ }^{50,62,63}$ and SLC26A1 $1{ }^{64}$ was detected. SLC26A2 immunoreactivity was localized to the epithelia of large pancreatic ducts in humans; however, no functional data are available on its activity. SLC26A3 and SLC26A6 were localized to the apical membrane of human PDECs ${ }^{62,63}$ and are thought to have important roles in the mechanism of pancreatic ductal $\mathrm{HCO}_{3}^{-}$secretion. ${ }^{23,48,50}$ SLC26A3 was first identified as a candidate tumor suppressor gene (down-regulated in adenoma $[D R A]),{ }^{65}$ which has $\mathrm{Cl}^{-}$transporter activity and is highly expressed at the luminal membrane of the intestinal epithelium. Mutations in the $D R A$ gene cause congenital $\mathrm{Cl}^{-}$diarrhea. ${ }^{66,67}$ Melvin et al ${ }^{68}$ showed that DRA functions as an electroneutral, $\mathrm{Na}^{+}$-independent $\mathrm{Cl}^{-} / \mathrm{HCO}_{3}^{-}$exchanger in the colon. Similarly, the guinea pig DRA protein was found to be electroneutral. ${ }^{64}$ In contrast, it has been demonstrated by Ko et $\mathrm{al}^{42}$ and by Shcheynikov et $\mathrm{al}^{69}$ that SLC26A3 functions as electrogenic $2 \mathrm{Cl}^{-} / 1 \mathrm{HCO}_{3}^{-}$exchanger in transfected HEK293 cells. Putative anion transporter 1 (PAT-1) was identified as a mouse kidney protein with $\mathrm{Cl}^{-} /$formate exchange activity. ${ }^{70}$ It is a major apical $\mathrm{Cl}^{-} / \mathrm{HCO}_{3}^{-}$exchanger in the small intestine and mediates the majority of prostaglandin E-stimulated $\mathrm{HCO}_{3}^{-}$secretion in the duodenum. ${ }^{71}$ On the basis of its localization in the apical membrane of the pancreatic duct and its function as a $1 \mathrm{Cl}^{-} / 2 \mathrm{HCO}_{3}^{-}$exchanger, ${ }^{42,69}$ PAT- 1 has been proposed to be a major contributor to apical $\mathrm{HCO}_{3}^{-}$secretion in the pancreatic duct. ${ }^{50,62,63}$ The electrogenic nature of the transporter could be species-dependent as Clark et al ${ }^{72}$ found that although mouse SLC26A6 mediates bidirectional electrogenic oxalate $/ \mathrm{Cl}^{-}$exchange, human SLC26A6-mediated oxalate transport appeared to be electroneutral. In microperfused guinea pig ducts, measurements of membrane potential and $\mathrm{Cl}^{-} / \mathrm{HCO}_{3}^{-}$exchange activity suggested a probable stoichiometry of $1: 2 .^{73}$ It is important to note that SLC26A3 and SLC26A6 expression and function have been shown to be regulated by CFTR. ${ }^{62}$ Although SLC26A11 expression has also been found in pancreatic ducts, the guinea pig isoform exhibited only $\mathrm{pH}$-dependent $\mathrm{Cl}^{-}$, oxalate, and sulfate transport, but it had no detectable $\mathrm{Cl}^{-} / \mathrm{HCO}_{3}^{-}$ exchange activity in Xenopus oocytes. ${ }^{64}$ Despite marked species differences among mammalian SLC26 polypeptides present in the pancreatic duct, the anion selectivity and substrate affinity of guinea pig SLC26 anion exchangers are generally similar to those of their human orthologs, but they differ in some of their pharmacological properties. ${ }^{64}$

\section{$\mathrm{Na}^{+} / \mathrm{HCO}_{3}^{-}$Cotransporter}

$\mathrm{HCO}_{3}^{-}$accumulation across the basolateral membrane of PDECs is mainly mediated by NBC, a member of the SLC4 family. NBC activity was first identified in the salamander Ambystoma tigrinum kidney ${ }^{74}$ and since has been demonstrated functionally in numerous other cell types including pancreas, ${ }^{75-77}$ colon, ${ }^{78}$ liver, ${ }^{79,80}$ and heart. ${ }^{81}$ The crucial role of $\mathrm{NBC}$ in $\mathrm{HCO}_{3}^{-}$ secretion is based on studies of isolated rat and guinea pig pancreatic ducts. ${ }^{75-77}$ Ishiguro et $\mathrm{al}^{77}$ showed that NBC contributes to approximately $75 \%$ of the $\mathrm{HCO}_{3}^{-}$uptake by guinea pig PDECs during stimulation with secretin. Furthermore, it has been documented that under resting conditions NBC mediates cellular $\mathrm{HCO}_{3}^{-}$efflux when the basolateral membrane potential is about $-70 \mathrm{mV}^{82}$; however, under secretin-stimulated conditions, the cotransporter mediates $\mathrm{HCO}_{3}^{-}$influx. ${ }^{83}$ The basolateral NBC isoform cloned from human pancreas and named $\mathrm{pNBC} 1$ by Abuladze et al ${ }^{19}$ transports $1 \mathrm{Na}^{+}$and $2 \mathrm{HCO}_{3}^{-}$in pancreatic ducts, but its stoichiometry is cell-type dependent ${ }^{84}$ and can be altered by PKA phosphorylation. ${ }^{85}$ All members of the superfamily of $\mathrm{Na}^{+}$-driven $\mathrm{HCO}_{3}^{-}$transporters were discovered and classified by Boron et al, ${ }^{86}$ who renamed it to NBCe1-B and identified 3 different splice variants (NBCe1-A, NBCe1-B, and $\mathrm{NBCe} 1-\mathrm{C}){ }^{86}$

$\mathrm{NBCe} 1-\mathrm{B}$, which is sometimes called $\mathrm{pNBC} 1$, is predominantly expressed in the pancreas. ${ }^{19} \mathrm{NBCe} 1-\mathrm{B}$ is an electrogenic transporter that uses the $\mathrm{Na}^{+}$gradient more efficiently than NHE1 to accumulate cytosolic $\mathrm{HCO}_{3}^{-}$, and indeed, NBCel-B transports the bulk of basolateral $\mathrm{HCO}_{3}^{-}$entry during ductal fluid and $\mathrm{HCO}_{3}^{-}$ secretion. ${ }^{5,6,77,83}$ The activity of NBCe1-B is regulated by multiple inputs, including IRBIT ${ }^{87,88}$ and the WNK/SPAK pathway. ${ }^{87} \mathrm{NBCe} 1-\mathrm{C}$ variant is mainly expressed in the glial cells of the brain. 89,90

Electroneutral NBC (named NBCn1-A or NBC3) is expressed on the luminal membrane of PDECs and plays a major role in $\mathrm{HCO}_{3}^{-}$salvage. ${ }^{19}$ In the resting state, secretory glands absorb $\mathrm{Na}^{+}$ and $\mathrm{HCO}_{3}^{-91}$; however, the transporters that play part in absorbing mechanisms of these ions across the luminal membrane of the pancreatic ducts have not been characterized in great detail. Nevertheless, NBCn1-A seems to be regulated by CFTR in a cAMP/PKA-dependent manner. ${ }^{91}$ Multiprotein complexes are formed between NBCn1-A and CFTR by PDZ domainmediated interactions, which makes it possible for CFTR to inhibit NBCn1-A activity during stimulated secretion. ${ }^{91}$ Actually inhibiting $\mathrm{HCO}_{3}^{-}$salvage transporters during secretion is quite logical, because otherwise they would counteract the effect of secretory transporters.

\section{$\mathrm{Na}^{+} / \mathrm{H}^{+}$Exchangers}

Human NHEs are members of the SLC9 gene family, which are a subgroup of the monovalent cation proton antiporter superfamily. ${ }^{92,93}$ NHEs are involved in numerous physiological processes, such as regulation of $\mathrm{pH}$ homeostasis of the cytosol and intracellular organelles. They ensure the major $\mathrm{Na}^{+}$absorbing mechanism in the kidney and gastrointestinal tract. ${ }^{94}$

NHE1 is ubiquitously expressed and is localized to the basolateral membrane of epithelial cells including PDECs. ${ }^{95}$ NHE1 is activated by acidic $\mathrm{pH}_{\mathrm{i}}$ levels and plays an indirect role in the mechanism of pancreatic ductal $\mathrm{HCO}_{3}^{-}$secretion by the backward transport of $\mathrm{H}^{+}$across the basolateral membrane. In most species, 
the inhibition of NHE1 by amiloride has minimal effect on secretin-stimulated pancreatic ductal fluid and $\mathrm{HCO}_{3}^{-}$secretion. ${ }^{96,97}$

NHE2 and NHE3 are expressed in the luminal membrane of interlobular and main mouse pancreatic ducts, which are responsible for a luminal $\mathrm{H}^{+}$efflux $\left(\mathrm{HCO}_{3}^{-}\right.$salvage $)$mechanism. ${ }^{98}$ In the resting state, the $\mathrm{pH}$ of pancreatic juice is acidic and contains high level of $\mathrm{CO}_{2}$, which indicate an active $\mathrm{H}^{+}$secretory process. $^{6}$ To clarify the role of NHEs in this mechanism, Lee et al ${ }^{98}$ carried out experiments by using NHE2 and NHE3 knockout mice. Approximately $45 \%$ of the luminal $\mathrm{H}^{+}$efflux was mediated by NHE3. Despite the expression of NHE2, its functional role could not be established. Interestingly, they identified a novel, HOE694 (amiloride analog)-sensitive, $\mathrm{Na}^{+}$-dependent $\mathrm{H}^{+}$efflux mechanism, which was responsible for the remaining (approximately $55 \%$ ) luminal $\mathrm{H}^{+}$efflux. Importantly, CFTR is in close interaction with NHE3 and also regulates its activity. ${ }^{40,91}$ It is likely that the activity of NHE3 is inhibited during $\mathrm{HCO}_{3}^{-}$secretion. The role of other potential NHE isoforms in ductal secretion/absorption needs further investigation.

\section{Aquaporins}

It was believed for a long time that water flow from the basolateral to the luminal side is solely driven by osmotic gradient via a paracellular pathway. However, nowadays, it is evident that water transport is also an actively mediated transcellular process. In most organisms, AQP water channels account for transcellular water permeability. ${ }^{99,100}$ Aquaporins are permeable not only to water, but also to small solutes such as cations and glycerol. ${ }^{99,100}$ There are at least 13 AQP genes (AQP0-AQP12) in mammalian cells $^{101}$; Delporte ${ }^{102}$ gives a nice overview of pancreatic AQP expression in different mammalian species. Briefly, mouse PDECs express abundant AQP1 and AQP5 at the apical membrane and AQP1 alone at the basolateral membrane. ${ }^{103}$ Marked expression of AQP1 and small amount of AQP5 were detected in isolated rat ductal cells by Ko et al. ${ }^{104}$ They also demonstrated that AQP1 was present in both luminal and basolateral membranes of interlobular PDECs. Almost all of the secretin-evoked pancreatic fluid secretion is thought to be mediated by AQP1 ${ }^{104}$ Similarly to that found in rats, human pancreatic ducts also express AQP1 in the luminal and basolateral membranes; however, AQP5 was detected only in the luminal membrane. ${ }^{105,106}$ Interestingly, both AQP1 and AQP5 were colocalized with CFTR at the apical membrane of intercalated duct cells. ${ }^{105}$ Thus, it is no wonder that guinea pig CFTR gene silencing by RNA interference reduces both CFTR and AQP1 expression in PDECs, which results in inhibition of pancreatic fluid secretion. ${ }^{107}$ Taken together, these observations suggest that AQP1 and AQP5 are the most important water channels in pancreatic ducts. The restoration of AQP expression by gene transfer may be beneficial as this has already been demonstrated in case of radiation-induced salivary hypofunction. ${ }^{108}$

\section{Other Enzymes, Transporters, Pumps, and Channels}

\section{Carbonic Anhydrases}

Carbonic anhydrases are a diverse group of intracellular and extracellular enzymes involved in pancreatic $\mathrm{HCO}_{3}^{-}$secretion. In fact, they are in close interaction and form complexes with other transporters (eg, SLC26A6, pNBC) involved in secretion. ${ }^{109,110}$ The nonspecific carbonic anhydrase inhibitor acetazolamide has been shown to significantly inhibit secretion. ${ }^{22}$ This may be due to a partial inhibition of basolateral $\mathrm{HCO}_{3}^{-}$uptake as seen in human pancreatic duct cells. ${ }^{49}$ Reverse transcriptase-polymerase chain reaction and immunohistochemistry confirmed the expression of carbonic anhydrase II, IV, IX, and XII in the human pancreas and/or in pancreatic ducts. ${ }^{11-113}$ Interestingly, the targeting of carbonic anhydrase IV to the apical plasma membrane of duct cells seems to be CFTR dependent. ${ }^{114,115}$

\section{$\mathrm{Na}^{+} / \mathrm{K}^{+}$-ATPase Pump and $\mathrm{K}^{+}$Channels}

The main driving forces for pancreatic electrolyte and fluid secretion are the basolaterally expressed $\mathrm{Na}^{+} / \mathrm{K}^{+}$-ATPase pump ${ }^{6,116,117}$ and $\mathrm{K}^{+}$channels, which produce the negative membrane potential that is essential for ductal anion secretion. ${ }^{4,118}$ Numerous types of $\mathrm{K}^{+}$channels are expressed in PDECs (including KCNN4, KCNMA1, KCNQ1, KCNH2, KCNH5, $\mathrm{KCNT} 1, \mathrm{KCNT} 2$, and $\mathrm{KCNK} 5$ ), which are discussed in detail by Hayashi and Novak ${ }^{118}$ and Venglovecz et al. ${ }^{119}$ Not all of these $\mathrm{K}^{+}$channels may be functional in the ducts, and in some cases, their localization is also a matter of question. Microelectrode and patch-clamp methods revealed functional maxi- $\mathrm{K}^{+}$ (BK) channels, intermediate-conductance $\mathrm{Ca}^{2+}$-activated $\mathrm{K}^{+}$ (IK) channels, and $\mathrm{pH} / \mathrm{HCO}_{3}^{-}$-sensitive $\mathrm{K}^{+}$channels in PDECs. ${ }^{118}$ Gray et $\mathrm{al}^{120}$ have identified a $\mathrm{Ca}^{2+}$-sensitive, voltage-dependent, maxi- $\mathrm{K}^{+}$channel on the basolateral membrane of rat pancreatic duct cells. In contrast, Venglovecz et $\mathrm{al}^{121}$ demonstrated maxi-K $\mathrm{K}^{+}$ channel expression on the luminal membrane of guinea pig PDECs. Interestingly, it has recently been shown that gastric and nongastric $\mathrm{H}^{+} / \mathrm{K}^{+}$pumps (expressed on the luminal and basolateral membranes) may also play part in the secretion by ducts. ${ }^{122}$ The effects of $\mathrm{Na}^{+} / \mathrm{K}^{+} / \mathrm{Cl}^{-}$cotransporter (NKCC) and $\mathrm{H}^{+}$ATPase may be important only in rodents (rat and mice) and pigs, respectively, so they are not discussed in the current review. ${ }^{11}$

\section{$\mathrm{Ca}^{2+}$-Activated CI Channels}

Besides CFTR, other anion channels such as $\mathrm{Ca}^{2+}$-activated $\mathrm{Cl}^{-}$channels (CaCCs) are localized on the luminal membrane of duct cells. ${ }^{123,124} \mathrm{Ca}^{2+}$-activated $\mathrm{Cl}^{-}$channels may play role in numerous physiological processes including smooth muscle contraction and fertilization and $\mathrm{HCO}_{3}^{-}$secretion in epithelial cells. ${ }^{125}$ The molecular identity of $\mathrm{CaCCs}$ in PDECs needs to be investigated. A likely candidate of ductal $\mathrm{CaCC}$ is called ANO1 (also called transmembrane member 16A, TMEM16A, or discovered on gastrointestinal stromal tumours 1 [DOG1]), which was shown to be expressed in the CAPAN-1 human PDECs line, ${ }^{126}$ and in centroacinar cells and small ducts of human pancreatic tissue. ${ }^{127}$ Recent observations reported that ANO1 anion selectivity is dynamically regulated by the $\mathrm{Ca}^{2+} /$ calmodulin complex. ${ }^{128}$ ANO1 becomes highly permeable to $\mathrm{HCO}_{3}^{-}$at high $\left[\mathrm{Ca}^{2+}\right]_{\mathrm{i}}$ via $\mathrm{Ca}^{2+}$ dependent interaction between ANO1 and calmodulin. ${ }^{128}$ Other $\mathrm{CaCC}$ candidates in PDECs belong to the bestrophin family members. hBest 1, hBest2, hBest3, and hBest 4 have been identified in the CF pancreatic duct cell line, CFPAC- $1 .{ }^{129} \mathrm{hBest} 1$ was expressed in the cell membrane and specific cytoplasmic domains and during its biosynthesis followed the classic secretory pathway. ${ }^{129}$ Knockdown of hBest 1 expression significantly decreased $\mathrm{Ca}^{2+}$-activated anion efflux from CFPAC-1 cells.

\section{REGULATION OF PANCREATIC DUCTAL SECRETION}

The exocrine pancreas secretes about 1 to $2.5 \mathrm{~L}$ of pancreatic juice daily. Body size, but not sex, influences the rate of $\mathrm{HCO}_{3}^{-}$and fluid secretion. ${ }^{130,131}$ The volume of secreted pancreatic fluid decreases with age, which has been confirmed by invasive ${ }^{131,132}$ and noninvasive techniques. ${ }^{133}$ In fact, both the secretory volume and $\mathrm{HCO}_{3}^{-}$output showed relatively steep decline after 20 years of age, so these need to be taken into consideration when evaluating the exocrine function of patients. The reduction in secretion may be due to age-related morphologic and functional changes of the pancreas. 
The control of pancreatic secretion is divided into cephalic, gastric, and intestinal phases, the latter of which is the most important with respect to ductal secretion. ${ }^{4}$ Resting secretion accounts for only a small fraction of the total secreted volume. The great majority of ductal fluid is secreted in response to stimulation (eg, that induced by a meal) and is regulated by both neural (enteropancreatic vagovagal reflex) and hormonal (most importantly by secretin) components. Obviously, it is evident that pancreatic ductal secretion is very precisely regulated not only by stimulatory (Fig. 2A), but also by inhibitory (Fig. 2B) pathways. ${ }^{134}$ Pancreatic ductal cells express many receptors for hormones and neurotransmitters, the activation of which can lead to either stimulation or inhibition of $\mathrm{HCO}_{3}^{-}$and fluid secretion via intracellular signaling pathways detailed below. The primary signaling systems are the cAMP/protein kinase A and $\mathrm{Ca}^{2+}$ pathways that mediate almost all secretory gland functions. ${ }^{135}$ An intimate interaction and crosstalk occur at multiple levels between these 2 pathways to control and fine tune the activity of each other. ${ }^{135}$

\section{Stimulatory Pathways}

\section{cAMP and cGMP Signaling}

Secretin, vasoactive intestinal peptide (VIP), and $\beta$-adrenergic receptor agonists are all coupled to adenylyl cyclase activation. Secretin is 1 of the most important physiological regulators of ductal $\mathrm{HCO}_{3}^{-}$secretion. In response to the passage of food (chyme) and to low duodenal $\mathrm{pH}$ (between 2 and 4.5), secretin is released from enteroendocrine cells of the duodenum into the circulation and intestinal lumen. ${ }^{136,137}$ Other factors involved in the release of secretin include high concentration of bile salts and fatty acids. ${ }^{138}$

The central role of secretin in stimulation of pancreatic $\mathrm{HCO}_{3}^{-}$secretion was suggested by Chey et al, ${ }^{137}$ who found

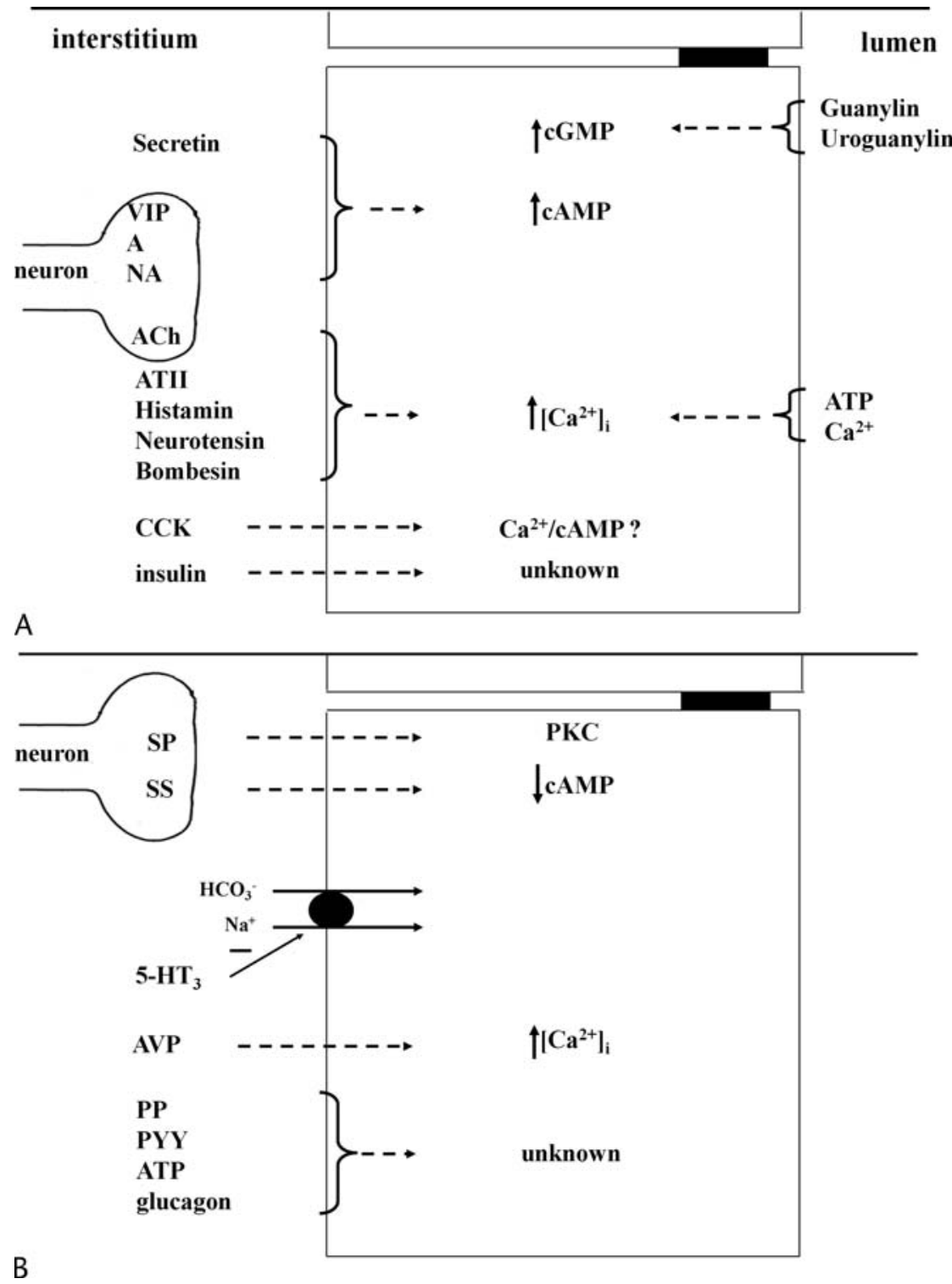

FIGURE 2. Regulation of pancreatic ductal secretion. A, Agonists which stimulate ductal secretion. B, Neurotransmitters and hormones which cause inhibition of ductal secretion. Intracellular messengers mediating their actions are shown. A, adrenaline; NA, noradrenaline; ACh, acethylcholine; ATII, Angiotensin II; CCK, cholecystokinin; SS, somatostatin; 5- $\mathrm{HT}_{3}$, serotonin; AVP, arginine-vasopressin. Based on Argent et al. ${ }^{11}$ 
an $80 \%$ inhibition of postprandial $\mathrm{HCO}_{3}^{-}$output by administering antisecretin antibodies. It has also been proposed that other factors, such as CCK stimulation and cholinergic vagal output via an enteropancreatic vagovagal reflex, contribute to the regulation of ductal secretion. ${ }^{4}$ This is based on the results of Gyr et al, ${ }^{139}$ who demonstrated that ductal secretion evoked by exogenous application of secretin is significantly lower than the extent observed during postprandial secretion. In fact, a number of publications point to the roles of CCK and vagal stimulation in secretin-induced secretion. ${ }^{140-142}$ Secretin stimulates pancreatic ductal fluid and $\mathrm{HCO}_{3}^{-}$secretion via increasing the activity of adenylate cyclase and the level of cAMP. High intracellular cAMP level consequently activates protein kinase $\mathrm{A},{ }^{143}$ which phosphorylates the regulatory (R) domain of CFTR. These events lead to the activation of CFTR and stimulation of secretion.

The secretory effects of VIP and sympathomimetics acting on $\beta$-adrenergic receptors are species dependent. Similarly to secretin, VIP increases the level of cAMP in guinea pig pancreatic ducts. ${ }^{144}$ In contrast, VIP exerts weak effects on cAMP accumulation $^{145}$ and fluid secretion in rats. ${ }^{146}$ The nonselective $\beta$-adrenergic receptor agonist isoprenaline stimulates fluid secretion in rat pancreatic ducts, ${ }^{147}$ but it has no effect on cAMP concentrations in guinea pig ducts. ${ }^{144}$

The intestinal peptide hormones guanylin and uroguanylin play role in the regulation of electrolyte and fluid secretion of pancreatic ducts via stimulation of guanylate cyclase $\mathrm{C}$ (GC-C). ${ }^{148,149}$ Guanylin, uroguanylin, and GC-C are expressed on the apical membrane of human and rat pancreatic ducts. ${ }^{148-150}$ Activation of GC-C by these peptides causes elevation of intracellular cGMP concentration. ${ }^{151}$ The increase in cGMP level stimulates cGMPdependent protein kinase II, ${ }^{152}$ which mediates stimulation of $\mathrm{CFTR}^{153}$ and finally elevates fluid and $\mathrm{HCO}_{3}^{-}$secretion. ${ }^{148,154}$

\section{$\mathrm{Ca}^{2+}$ Signaling}

Regulation of pancreatic ductal intracellular $\mathrm{Ca}^{2+}$ concentration $\left(\left[\mathrm{Ca}^{2+}\right]_{\mathrm{i}}\right)$ is mediated by various pumps and channels. ${ }^{36}$ Acetylcholine (the main neurotransmitter of the parasympathetic nervous system), ATP, angiotensin II, ${ }^{155}$ and histamine ${ }^{156}$ effectively stimulate ductal $\mathrm{HCO}_{3}^{-}$secretion via elevation of $\left[\mathrm{Ca}^{2+}\right]_{\mathrm{i}} \cdot{ }^{157,158}$ Furthermore, it has been shown that the $\mathrm{Ca}^{2+}$ ionophore ionomycin also activates ductal fluid secretion, suggesting that elevation of $\left[\mathrm{Ca}^{2+}\right]_{\mathrm{i}}$ alone is sufficient to evoke the stimulatory response. ${ }^{157}$ It has been demonstrated that $\mathrm{Ca}^{2+}$-sensing receptor was highly expressed on the rat pancreatic duct and the luminal membrane of CAPAN-1 cells. ${ }^{159,160}$ Furthermore, it was also confirmed that $\mathrm{HCO}_{3}^{-}$secretion is stimulated by luminal administration of $\mathrm{Ca}^{2+}$-sensing receptor agonist gadolinium $\left(\mathrm{Gd}^{3+}\right)$ via elevation of $\left[\mathrm{Ca}^{2+}\right]_{\mathrm{i} .}{ }^{159}$

Pancreatic ducts are innervated by both peptidergic and cholinergic neurons, so it is not surprising that acetylcholine plays a role in the regulation of ductal secretion. It was shown that M2 and M3 subtypes of muscarinic receptors are present in pancreatic ducts of guinea pig, and their density is 7 times greater than that found in acinar cells. ${ }^{161}$ Acetylcholine directly stimulates $\mathrm{HCO}_{3}^{-}$secretion in guinea pig and in rat, which is abolished by atropine and removal of extracellular $\mathrm{Ca}^{2+}$, and the maximal secretory response is similar to that caused by secretin. ${ }^{157,158} \mathrm{The}\left[\mathrm{Ca}^{2+}\right]_{\mathrm{i}}$ response evoked by acetylcholine resulted from both mobilization of $\mathrm{Ca}_{i}^{2+}$ stores and influx of $\mathrm{Ca}^{2+}$ from the extracellular space. ${ }^{157}$ In addition, the cholinergic neurotransmitter potentiates the effect of secretin on secretion in isolated rat pancreatic ducts. ${ }^{162}$

Several purines and pyrimidines found in the extracellular fluid (ie, ATP, ADP, adenosine, UTP, and UDP) can activate intracellular $\mathrm{Ca}^{2+}$ signaling via purinergic receptors (P2Rs). Purinergic receptors are classified into metabotropic $\mathrm{P} 2 \mathrm{Y}$ and ionotropic P2X receptors. ${ }^{163} \mathrm{P}_{2} \mathrm{Y}_{2}, \mathrm{P}_{2} \mathrm{Y}_{4}, \mathrm{P}_{2} \mathrm{X}_{1}, \mathrm{P} 2 \mathrm{X}_{4}, \mathrm{P} 2 \mathrm{X}_{7}$, and probably other $\mathrm{P} 2 \mathrm{Rs}$ such as $\mathrm{P} 2 \mathrm{Y}_{1}$ and $\mathrm{P} 2 \mathrm{Y}_{11}$ are expressed in pancreatic ducts. ${ }^{164}$ The distribution of different receptor subtypes in pancreatic duct cells is controversial but is probably species dependent. P2Y receptors are likely localized to both apical and basolateral membranes, whereas P2X receptors are expressed only on the apical membrane. ${ }^{164,165}$ Ishiguro et al ${ }^{166}$ demonstrated that apical and also basolateral administration of ATP evokes elevation of $\left[\mathrm{Ca}^{2+}\right]_{\mathrm{i}}$. They also showed that luminal application of ATP stimulated fluid and $\mathrm{HCO}_{3}^{-}$secretion. This stimulatory effect of ATP is based on evidence that apical administration of ATP/UTP activates $\mathrm{CFTR}, \mathrm{Cl}^{-} / \mathrm{HCO}_{3}^{-}$exchangers, and $\mathrm{CaCCs}$ and also regulates $\mathrm{K}^{+}$ channels on CAPAN-1 cells. ${ }^{126,167}$ In contrast, when ATP was added from the basolateral side, the result was inhibition of either spontaneous or secretin-stimulated secretion in guinea pig pancreatic duct. ${ }^{166}$ This finding was confirmed by Szücs et al ${ }^{168}$ on the human CAPAN-1 duct cells. Purinergic ligands released from nerve terminal at the basolateral membrane or from zymogen granules of acinar cells can also stimulate P2Rs. ${ }^{165,169}$

The systemic renin-angiotensin system is essential for the regulation of blood pressure and electrolyte and fluid balance. In pancreatic duct cells, angiotensin II regulates anion secretion via activation of angiotensin II type 1 receptors. ${ }^{155}$ It has been documented that angiotensin II dose-dependently increases short-circuit current of CFPAC-1 cell line, the effect of which is completely abolished by losartan, an angiotensin II type 1 receptor blocker and depletion of $\mathrm{Ca}_{\mathrm{i}}^{2+}$. 170

Several other agonists (bombesin, neurotensin) can influence ductal $\left[\mathrm{Ca}^{2+}\right]_{\mathrm{i}}$ and can stimulate pancreatic secretion. For example, bombesin directly stimulates ductal $\mathrm{HCO}_{3}^{-}$and fluid secretion in guinea pig via activation of gastrin-releasing, peptide-preferring bombesin receptor. ${ }^{158}$ A number of publications proved that $\mathrm{CCK}$ increases $\mathrm{HCO}_{3}^{-}$and water secretion and potentiates the effects of secretin on pancreatic ducts. ${ }^{140,158}$ The direct effect of CCK on guinea pig PDECs has been demonstrated by Szalmay et al, ${ }^{158}$ who showed that the secreted fluid stimulated by $\mathrm{CCK}$ is rich in $\mathrm{HCO}_{3}^{-}$and is mediated by $\mathrm{CCK} 1$ receptor subtypes. The effect of $\mathrm{CCK}$ on $\left[\mathrm{Ca}^{2+}\right]_{\mathrm{i}}$ is controversial. It has been demonstrated that CCK significantly increased cytosolic $\mathrm{Ca}^{2+}$ concentration up to 50 -fold over baseline in rat. ${ }^{171}$ In another study, CCK did not cause any marked and reproducible increases in $\left[\mathrm{Ca}^{2+}\right]_{\mathrm{i}}$ on rat and guinea pig pancreatic ducts. ${ }^{172}$

\section{Unknown Signaling}

Besides other gastrointestinal hormones, insulin also plays an important role in the regulation of ductal secretion. Initially, Hasegawa et $\mathrm{al}^{173}$ demonstrated a potentiating effect of insulin on pancreatic juice secretion in an isolated perfused rat pancreas model. In contrast, Berry and Fink ${ }^{174}$ and HowardMcNatt et $\mathrm{al}^{175}$ showed that the exogenous administration of insulin inhibited secretin-stimulated pancreatic $\mathrm{HCO}_{3}^{-}$secretion via a neurally mediated mechanism in dogs. The results of some other studies actually suggest that endogenous insulin promotes pancreatic secretion. Intravenous administration of glucose (resulting in elevated endogenous plasma insulin concentration) seems to increase secretin-stimulated pancreatic exocrine secretion in humans. ${ }^{176}$ In accord with the latter results, stimulated pancreatic secretion was markedly blocked by treatment with rabbit anti-insulin serum, whereas it was not influenced by normal rabbit serum in rats ${ }^{177}$ and dogs. ${ }^{178}$ Because exogenous glucose administration (used to create systemic hyperinsulinemia via endogenous 
pancreatic insulin production) did not inhibit secretin-induced pancreatic $\mathrm{HCO}_{3}^{-}$secretion, Simon et al ${ }^{179}$ proposed that because exogenous insulin exerts feedback regulation on the pancreas, it likely suppresses endogenous insulin secretion (which likely mediates the inhibitory response reported by Berry and Fink, ${ }^{174}$ and Howard-McNatt et al. ${ }^{175}$ Taken together, although exogenous insulin administration may have an inhibitory effect on ductal secretion, endogenous insulin exerts a stimulatory effect. The effect of insulin seems to be independent of changes in intracellular cAMP concentrations. ${ }^{144}$

\section{Inhibitory Pathways}

The inhibitory regulation of pancreatic secretion is mediated via direct (on the ductal cells) or indirect mechanisms. The inhibition of secretion may be physiologically important in reducing secretion back to the basal level after a meal and also in maintaining the integrity of the pancreas via limiting hydrostatic pressure within the duct lumen. ${ }^{180}$ This is crucial in case of ductal obstruction as the elevated pressure may seriously damage the pancreas. Unfortunately, the authors' knowledge of inhibitory mediators is scarce, especially concerning their molecular mechanisms of inhibition, but numerous substances have been shown to negatively regulate secretion, which are discussed below. For a more detailed overview of inhibitory substances, refer to the authors' earlier publication. ${ }^{180}$

\section{Substance P}

The neuropeptide substance $\mathrm{P}(\mathrm{SP})$ is a potent inhibitor of pancreatic ductal $\mathrm{HCO}_{3}^{-}$and fluid secretion. Substance $\mathrm{P}$ strongly inhibits in vivo pancreatic fluid secretion in multiple species such as the dog, ${ }^{181,182}$ rat, and mouse. ${ }^{183}$ Moreover, SP inhibits both basal- and secretin-stimulated fluid secretion of isolated rat and guinea pig pancreatic ducts in vitro, ${ }^{146,184}$ suggesting a direct action of SP on pancreatic duct cells. The inhibitory effect of SP is dose dependent in rat and was partially reversed by spantide, a neurokinin (NK) receptor antagonist. ${ }^{146}$ Accordingly SP exerts its inhibitory effect via the activation of $G$ protein-coupled NK receptors. Kemény et al ${ }^{185}$ demonstrated that all $3 \mathrm{NK}$ receptors are expressed in the luminal membrane, whereas NK2 and NK3 receptors were also detected on the lateral membranes of guinea pig pancreatic ductal cells. Furthermore, both of the laterally expressed NK receptors mediate the inhibitory effect of SP on isolated guinea pig pancreatic duct. ${ }^{185}$ Substance $\mathrm{P}$ binding to NK receptors activates PKC isoforms, which are expressed in PDECs and mediate the inhibition of $\mathrm{HCO}_{3}^{-}$secretion by modulating an SLC26 $\mathrm{Cl}^{-} / \mathrm{HCO}_{3}^{-}$exchanger. ${ }^{184,186}$ To confirm that the effect of SP is indeed mediated by PKC, the highly selective, cell-permeable PKC inhibitor bisindolylmaleimide was used. ${ }^{186}$

\section{Serotonin}

5-Hydroxytryptamine (5-HT)-reactive cells with morphological characteristics of enterochromaffin cells are present throughout the duct system, that is, the main, intralobular, and interlobular ducts of guinea pigs. ${ }^{187}$ In isolated interlobular ducts, basolateral administration of 5-HT strongly but reversibly inhibited secretin- and ACh-stimulated fluid secretion as well as spontaneous $\left(\mathrm{HCO}_{3}^{-}\right.$-dependent) secretion. ${ }^{187}$ The inhibition is mediated by the $5-\mathrm{HT}_{3}$ receptor, a ligand-gated, nonselective cation channel. Luminal administration of 5-HT failed to affect basal and secretin-stimulated fluid secretion, suggesting that only basolateral, but not luminal, 5-HT receptors mediate the inhibition of fluid secretion. ${ }^{187}$ The inhibition is probably due to the reduced uptake of $\mathrm{HCO}_{3}^{-}$via $\mathrm{Na}^{+}-\mathrm{HCO}_{3}^{-}$cotransport across the basolateral membrane. The enterochromaffin cells in the pancreatic duct may function as intraductal pressure sensors and regulate ductal fluid secretion. When the intraluminal pressure of pancreatic ducts increases, 5-HT is released into the interstitium from the ductal enterochromaffin cells, and the released 5-HT binds to $5-\mathrm{HT}_{3}$ receptors on the basolateral membrane of duct cells and inhibits fluid secretion. ${ }^{187}$ This may be a key mechanism in maintaining the integrity of the pancreatic tissue.

\section{Arginine Vasopressin}

Arginine vasopressin plays a key role in the fluid homeostasis of mammals. In the pancreas, 2 early publications suggested that arginine vasopressin inhibits pancreatic secretion in an indirect manner. ${ }^{188,189}$ Beijer et $a^{188}$ demonstrated that the vasoconstriction caused by arginine vasopressin decreases blood flow and reduces the oxygen consumption of the pancreas in anesthetized dogs. Few years later, Kitagawa et $\mathrm{al}^{189}$ showed that exogenous administration of vasopressin caused dosedependent inhibition of pancreatic juice flow and $\mathrm{HCO}_{3}^{-}$output by elevation of plasma osmolality in conscious dog. Furthermore, arginine vasopressin also inhibits secretin-stimulated fluid secretion in isolated guinea pig pancreatic ducts via elevation of $\left[\mathrm{Ca}^{2+}\right]_{\mathrm{i}}$ from intracellular $\mathrm{Ca}^{2+}$ stores. ${ }^{190}$

\section{Somatostatin}

Somatostatin is secreted from several locations including the gastrointestinal tract (eg, the stomach, the intestine, and the delta cells of pancreas) and the central nervous system. Somatostatin was first identified in the brain by Brazeau et $\mathrm{al}^{191}$ in 1973, and its function was related to inhibition of growth hormone secretion; thus, this peptide is also known as a growth hormone-inhibiting hormone. Since then, it has been demonstrated that somatostatin has a wide range of inhibitory functions. The exogenous administration of somatostatin inhibited pancreatic $\mathrm{HCO}_{3}^{-}$secretion induced by meal and also reduced the secretin-stimulated pancreatic $\mathrm{HCO}_{3}^{-}$secretion. ${ }^{173,192-196}$ Konturek et $\mathrm{al}^{195}$ demonstrated that the somatostatin analog cyclosomatostatin caused dose-dependent inhibition of pancreatic $\mathrm{HCO}_{3}^{-}$secretion via partially direct inhibitory effect on exocrine pancreas and the reduction of secretin release in dogs. The indirect inhibitory mechanism of somatostatin was confirmed by the observations of Kuvshinoff et al, ${ }^{197}$ who demonstrated the role of intrapancreatic cholinergic mechanism in the inhibitory effect of somatostatin on secretin-stimulated $\mathrm{HCO}_{3}^{-}$ secretion. Furthermore, somatostatin significantly reduced the effects of secretin on cyclic AMP level of pancreatic duct cells via inhibition of adenylyl cyclase activity. ${ }^{144}$

\section{Pancreatic Polypeptide and Peptide YY}

Pancreatic polypeptide (PP) and peptide YY (PYY) are structurally related peptide hormones. In fact, PP is derived from duplication of the PYY gene. ${ }^{198}$ Both PP and PYY are released in response to intake of food. ${ }^{199}$ Pancreatic polypeptide is secreted by PP cells of the Langerhans islets. ${ }^{200}$ It has been shown that the physiologic function of $\mathrm{PP}$ is to inhibit pancreatic $\mathrm{HCO}_{3}^{-}$secretion in response to meal and secretin. ${ }^{201-203}$ Konturek et $\mathrm{al}^{201}$ demonstrated marked differences in the effect of PP on the exocrine pancreas of man and dog. Pancreatic polypeptide administration caused dose-dependent inhibition of secretin-stimulated pancreatic fluid and $\mathrm{HCO}_{3}^{-}$secretion in dog, but not in human. Similarly to this observation, Lonovics et $\mathrm{al}^{202}$ have also shown that PP reduced the endogenously stimulated pancreatic secretion in a dose-dependent manner, whereas the release of CCK and secretin was not affected. Based on these results, they suggested that 
the inhibitory effect of PP is probably direct and that it is not mediated via inhibition of CCK or secretin release. ${ }^{202}$

Peptide YY is secreted by L cells localized in the mucosa of gastrointestinal tract, especially in ileum and colon. ${ }^{204}$ It plays fundamental roles is numerous physiological processes, including inhibition of gastric acid and meal-stimulated pancreatic fluid and $\mathrm{HCO}_{3}^{-}$secretion; furthermore, it increases water and electrolyte absorption in the colon..$^{205,206}$ Exogenous application of PYYalso reduced secretin- and CCK-stimulated secretion in $\operatorname{dog}^{207}$ The inhibitory action of PYY on pancreatic secretion is likely to be indirect; thus, it is fully mediated by the vagal efferent nerve. ${ }^{208}$

\section{Glucagon}

Glucagon is secreted by alpha cells of the Langerhans islets and is known to have an essential role in the regulation of glucose metabolism. Besides this important function, the exogenous administration of glucagon also inhibits stimulated pancreatic $\mathrm{HCO}_{3}^{-}$secretion in rats, ${ }^{173}$ dogs, ${ }^{209-212}$ cats, ${ }^{213}$ and humans. ${ }^{214,215}$ Generally speaking, the inhibitory effect of glucagon on digestive enzyme output is greater than that on pancreatic secretory volume and bicarbonate output. Glucagon had no effect on the levels of endogenously released secretin. ${ }^{211}$ This observation suggests that the inhibitory effect of glucagon on pancreatic secretion is not mediated via inhibition of secretin release. In addition, glucagon did not significantly alter resting or secretin-stimulated cyclic AMP levels in isolated guinea pig pancreatic duct segments. ${ }^{144}$

\section{Regulatory Proteins Involved in Epithelial Fluid and $\mathrm{HCO}_{3}^{-}$Secretion}

\section{PDZ-Based Adaptors}

Numerous PDZ domain-containing transporters play a fundamental role in the $\mathrm{HCO}_{3}^{-}$transport mechanism of pancreatic ducts via formation of protein complexes. PDZ stands for the first letters of 3 proteins that were initially shown to possess such domains: postsynaptic density protein (PSD95), Drosophila disc large tumor suppressor (Dlg1), and zonula occludens 1 protein $(\mathrm{ZO}-1)$. PDZ domain is a common structural unit of 80 to 90 amino acids that mediates protein-protein interactions by binding to short peptide sequences, most often in the $\mathrm{C}$ termini of target proteins. ${ }^{216}$ PDZ domains are responsible for targeting and trafficking of several membrane proteins such as receptors, transporters, channels, and adhesion proteins, through their PDZ-binding motifs. ${ }^{217}$ Furthermore, they bind to the PDZ domains of other proteins and develop multiprotein scaffolding networks. ${ }^{217}$

One of the PDZ proteins that is important in epithelial transport is the NHERF family. NHERF-1 (also known as ezrin-binding protein of $50 \mathrm{kd}$ [EBP50]) is a scaffolding protein, which tethers several membrane protein to apical actin cytoskeleton in polarized epithelia via ezrin. ${ }^{28}$ The adapter protein has been shown to bind to the PDZ-binding motifs of CFTR $\mathrm{Cl}^{-}$channel, NHE3, $\beta_{2}$-adrenoreceptor, ${ }^{218,219}$ and Slc26 family anion exchangers DRA (Slc26A3) 220 and PAT-1 (Slc26A6). ${ }^{63}$ In addition, NHERF-1 facilitates the formation of multiprotein complexes, which is fundamental for the adequate function of transporters, channels, and receptors. ${ }^{43}$ Therefore, it is not surprising that NHERF-1 is involved in numerous physiological processes such as the regulation of phosphate transport in the kidney, ${ }^{221}$ hepatic Mrp2 expression and function, ${ }^{222}$ protein kinase D activity, ${ }^{223}$ or trafficking of $\beta_{2}$-adrenergic receptors. ${ }^{224}$ To confirm the role of NHERF-1 in the pancreas, we demonstrated that the genetic deletion of NHERF-1 greatly reduced the translocation of CFTR to the luminal pancreatic ductal cell membrane and also decreased both in vitro and in vivo pancreatic $\mathrm{HCO}_{3}^{-}$and fluid secretion. ${ }^{225}$ Other studies have identified the fundamental role of NHERF1 and NHERF2 in the regulation of the luminal $\mathrm{HCO}_{3}^{-}$salvage transporters NHE3 and NBCn1-A via formation of multiprotein complexes with CFTR. ${ }^{40,91,226}$ This interaction may also be important in inhibition of these salvage transporters during secretion.

Moreover, pancreatic duct cells express several other scaffold proteins with PDZ domains, such as Shank2, S-SCAM, SAP97, and PSD-95. ${ }^{6,216,217}$ Shank2 is localized to the apical pole of pancreatic duct cells and is involved in the regulation of the expression and activities of CFTR and NHE3 $3^{6,216,227}$

\section{With-No-Lysine and Sterile 20-Like Kinases}

Recent publications suggest that WNK and SPAK have essential roles in the regulation of salt homeostasis and blood pressure via modulation of the activity of diverse ion transporters. ${ }^{228-230} \mathrm{In}$ fact, the main function of WNKs is the regulation of $\mathrm{Na}^{+}, \mathrm{K}^{+}, \mathrm{Cl}^{-}$, $\mathrm{HCO}_{3}^{-}$, and $\mathrm{Ca}^{2+}$ transporters in epithelia ${ }^{231-233}$ either by modulating their surface expression via promoting their endocytosis or by regulating their activity. ${ }^{12,234}$ It is likely that WNKs do not act directly on the ion transporters, but they activate downstream kinases SPAK and OSR $1 .{ }^{6}$ The activated SPAK/OSR1 phosphorylates the ion transporters and evokes their endocytosis. ${ }^{230}$

In pancreatic ducts, WNKs act through SPAK to control the activities of NBCe1-B and CFTR, and knockdown of WNKs and SPAK increases pancreatic ductal secretion. ${ }^{235}$ The WNK/SPAK pathway appears to have dual function in pancreatic ducts in the resting and stimulated states. ${ }^{6}$ Under resting conditions, WNK SPAK pathway reduces surface expression and activity of transporters (such as CFTR, SLC26 anion exchangers, and NBCe-1B), which will overall reduce pancreatic ductal fluid and $\mathrm{HCO}_{3}^{-}$ secretion. ${ }^{34,87,235,236}$ In the stimulated state, when $\left[\mathrm{Cl}^{-}\right]_{\mathrm{i}}$ is low (in the distal ducts), the WNK/SPAK pathway has an opposite effect. In this case, the activation of the WNK1/SPAK resulted in increased $\mathrm{HCO}_{3}^{-}$permeability of CFTR (making it primarily an $\mathrm{HCO}_{3}^{-}$channel) and inhibited apical $\mathrm{Cl}^{-} / \mathrm{HCO}_{3}^{-}$exchange activity (that may reabsorb $\mathrm{HCO}_{3}^{-}$from the lumen). ${ }^{6,34}$

\section{IP3 Receptor-Binding Protein Released With $\mathrm{IP}_{3}$}

IRBIT was identified as a protein that interacts with the $\mathrm{IP}_{3^{-}}$ binding domain of $\mathrm{IP}_{3}$ receptors $\left(\mathrm{IP}_{3} \mathrm{R}\right){ }^{237}$ It suppresses the activation of $\mathrm{IP}_{3} \mathrm{R}$ and inhibits $\mathrm{IP}_{3}$-induced $\mathrm{Ca}^{2+}$ release by competing with $\mathrm{IP}_{3}$ binding on the $\mathrm{NH}_{2}$-terminal domain of the $\mathrm{IP}_{3}$ receptor. ${ }^{238,239}$ Besides its other diverse functions, accumulating evidence from the groups of Muallem and Mikoshiba suggests that IRBIT has an essential role in the regulation of epithelial $\mathrm{HCO}_{3}^{-}$secretion. ${ }^{37,87,88,240,241}$ IRBIT aggregates at the apical pole of the pancreatic duct, ${ }^{87}$ where expression of $\mathrm{IP}_{3} \mathrm{Rs}$ is also high. IRBIT antagonizes the effect of the WNK/SPAK pathway and stimulates ductal secretion in 2 ways: it increases the cell surface expression and also the activities of $\mathrm{Cl}^{-}$and $\mathrm{HCO}_{3}^{-}$ transporters. ${ }^{12,235}$ It has been reported that IRBIT interacts with and regulates the activities of CFTR, SLC26A6 and possibly NHE3 on the apical pole, and NBCe1-B on the basal part of the ductal cells. The exact regulatory mechanism mediated by IRBIT is only partly understood, but it seems that IRBIT activates basolateral and apical transporters by different mechanisms. Shirakabe et $\mathrm{al}^{88}$ demonstrated that IRBIT induces conformational changes in $\mathrm{pNBCe} 1-\mathrm{B}$, which results in dissociation of its autoinhibitory domain. In contrast, IRBIT activates CFTR by direct interaction and reduces the close-duration time of CFTR and thus increases CFTR open probability. ${ }^{6,87}$ Importantly, IRBIT also acts as a conductor to mediate synergism between $\mathrm{Ca}^{2+}$ and 
cAMP signaling pathways in regulating the activation of CFTR and SLC26A6. ${ }^{37}$

\section{PATHOPHYSIOLOGICAL ROLE OF PANCREATIC DUCTAL SECRETION}

\section{Cystic Fibrosis}

The secretory function of the pancreatic ductal system is rather markedly affected by $\mathrm{CF}$, which is the most common fatal autosomal recessive disease in white population. Cystic fibrosis is caused by the absence or dysfunction of CFTR, a critical regulator of $\mathrm{HCO}_{3}^{-}$secretion. Almost $2000 \mathrm{CF}$-causing mutations have been identified in the $c f t r$ gene. ${ }^{242}$ Mutations are divided into 6 different classes according to mechanisms of CFTR dysfunction: defective protein production (I), defective protein processing (II), defective channel regulation (III), defective channel conduction (IV), reduced protein synthesis (V), and reduced protein stability (VI). The most common cftr mutation, the deletion of phenylalanine at position 508 (delF508-CFTR), was identified in 1989. ${ }^{24}$ This mutation primarily results in CFTR misfolding and degradation (class II), but it also shows other defects of classes III and VI. ${ }^{27,28,242-244}$ Although the life expectancy of individuals with CF has increased dramatically in the past decades, the average age of death (caused by respiratory failure) is still about 40 years. ${ }^{245}$ The disorder affects all epithelia expressing CFTR and presents with exocrine pancreatic insufficiency, an increase in sweat $\mathrm{NaCl}$ concentration, male infertility, and airway disorder. ${ }^{28}$ The major defect in $\mathrm{CF}$ is the inability to maintain luminal hydration of the lung, pancreas, and epididymis, which leads to thick and viscous fluid formation plugging the affected organs that will cause massive damage. ${ }^{246,247}$ The deficient ductal electrolyte and fluid secretion causes the pancreatic juice of CF patients to become acidic. ${ }^{4}$ This will contribute to precipitation of mucins and premature digestive enzyme activation inside the ductal lumen, resulting in the characteristic pancreatic cyst formation and scarring (fibrosis). ${ }^{248}$ The destruction of acinar cells eventually leads to pancreatic insufficiency, the degree of which can range from mild to severe depending on the cftr mutation. ${ }^{249,250}$

Because at least part of $\mathrm{HCO}_{3}^{-}$secretion is coupled to $\mathrm{Cl}^{-}$ transport, it is no wonder that cftr mutations resulting in reduced $\mathrm{Cl}^{-}$conductance can markedly impact the secretory process. However, a number of disease-causing cftr mutations were found that support normal or even elevated $\mathrm{Cl}^{-}$channel activity, but had no (in pancreatic insufficient patients) or reduced (in pancreatic sufficient patients) $\mathrm{HCO}_{3}^{-}$transport. ${ }^{39}$ This may be due to defective activation of SLC26 anion exchangers catalizing $\mathrm{HCO}_{3}^{-}$secretion by mutant CFTR. ${ }^{42}$ These results also suggest that in some cases correction of $\mathrm{Cl}^{-}$transport may not necessarily be enough to restore $\mathrm{HCO}_{3}^{-}$secretion.

Recently, small-molecule drug-like CFTR correctors and potentiators have been utilized in clinical trials involving CF patients to compensate for trafficking and gating defects, respectively. ${ }^{251,252}$ Cystic fibrosis transmembrane conductance regulator correctors (eg, 4-phenyl-butyrate or VX-809) are targeted at protein misprocessing, whereas potentiators (eg, ivacaftor) are used to restore $\mathrm{Cl}^{-}$channel activity. Some compounds have both corrector and potentiator effects, which could be especially useful in treating the most common form (F508del) of cftr mutation. Gene transfer-based therapies (to introduce wild-type CFTR into cells expressing defective CFTR) have also offered hopeful perspectives in resolving the problem of CF. Because the majority of the morbidity and mortality in $\mathrm{CF}$ is a result of lung disease, most efforts in this field have focused on gene transfer to the airway. We have shown that wild-type $c f t r$ transfer using a recombinant Sendai vector significantly increased the apical $\mathrm{Cl}^{-} / \mathrm{HCO}_{3}^{-}$exchange activity of CFPAC-1 duct cells derived from the adenocarcinoma of a CF patient. ${ }^{50}$ Therefore, restoration of pancreatic ductal secretion by wild-type CFTR should be beneficial in CF patients. Because the receptor for the Sendai virus is localized to the apical membrane of PDECs, a retrograde injection of this vector into the pancreatic duct would be necessary in vivo. This is not necessarily ideal, so other vectors may be more appropriate in patients. For example, Griffin et $\mathrm{al}^{253}$ have successfully transduced PDECs of newborn pigs through the umbilical artery with an adenoassociated virus serotype 9 vector.

To study the pathogenesis and therapy of CF, most commonly murine models are used. Although we have learned a lot from using CFTR knockout mice, the utilization of these animals has numerous limitations such as anatomic, immunologic, and disease phenotypic differences between human and mice. ${ }^{254-256}$ Importantly, CF mice exhibit milder pancreatic pathology compared with patients. ${ }^{255}$ This may be due to residual CFTR activity and/or the presence of alternate $\mathrm{Cl}^{-}$secretory pathways such as $\mathrm{Ca}^{2+}$-activated $\mathrm{Cl}^{-}$channels. In fact, patch clamp experiments have shown that $\mathrm{Ca}^{2+}$-activated $\mathrm{Cl}^{-}$conductance is much greater than that caused by CFTR in mouse duct cells. ${ }^{124}$ Human pancreatic duct cells also express $\mathrm{Ca}^{2+}$-activated $\mathrm{Cl}^{-}$channels at high levels, ${ }^{257}$ which makes them a potential therapeutic target in $\mathrm{CF}$ patients. To complicate things further, pancreatic ducts isolated from CFTR-null mice still secreted electrolytes and fluid, which

TABLE 1. Disease Phenotypes of the Pig and Ferret Cystic Fibrosis Models Compared With the Human Disease in Newborns

\begin{tabular}{|c|c|c|c|}
\hline & Pig & Ferret & Human \\
\hline Lung histology & Normal & $\begin{array}{l}\text { Infected by streptococci } \\
\text { and staphylococci }\end{array}$ & Normal \\
\hline Pancreatic destruction & Very severe & Mild & Mild \\
\hline Meconium ileus & $100 \%$ & $75 \%$ & $15 \%$ \\
\hline Liver & Focal biliary cirrhosis & $\begin{array}{l}\text { Histologically normal, } \\
\text { but elevated LFT }\end{array}$ & $\begin{array}{c}\text { Histologically normal, } \\
\text { but elevated LFT }\end{array}$ \\
\hline Gallbladder & $\begin{array}{l}\text { Mucus- and bile-filled } \\
\text { microgallbladder }\end{array}$ & Normal & $30 \%$ Microgallbladder \\
\hline Vas deferens & Intact & Absent or degenerate & Intact \\
\hline
\end{tabular}

Newborn pigs and ferrets lacking CFTR exhibit defective chloride transport which leads to numerous alterations in different organs affected by cystic fibrosis. Notably, tissue damage progresses throughout the life of the diseased animals/humans.

LFT indicates liver function tests. 
could not be attributed to $\mathrm{Ca}^{2+}$-activated $\mathrm{Cl}^{-}$channels. ${ }^{258}$ Chelation of intracellular $\mathrm{Ca}^{2+}$ did not influence stimulated fluid secretion in CF versus wild-type ducts. Further studies are needed to identify the mechanism responsible for the CFTR-independent fluid transport.

The recent development of $\mathrm{CF}$ pigs ${ }^{259}$ and CF ferrets ${ }^{260}$ provides better disease models as they show more similarities to the human CF phenotype. Newborn pigs and ferrets lacking CFTR exhibited defective chloride transport and develop meconium ileus, pancreatic pathology, and liver involvement (focal biliary cirrhosis or elevated liver function tests), mimicking abnormalities seen in newborn humans with CF (Table 1). Meconium ileus is potentially lethal unless treated by surgery. Seventy-five percent of the CFTR-deficient ferrets failed to pass meconium and died within 48 hours of life because of intestinal perforation and sepsis. ${ }^{260}$ Similarly, CF pigs required ileostomy to relieve meconium ileus to live beyond the first few days after birth. ${ }^{259}$ Fetal and newborn CF pigs had very severe pancreatic destruction (whereas most CF patients at this stage have only mild lesions) and exhibited significantly lower volume and $\mathrm{pH}$ of pancreatic fluid, whereas protein concentration was more than 5 -fold higher versus the control. ${ }^{261}$ They also had significantly increased expression of proinflammatory, complement cascade, and profibrotic genes versus non-CF pigs. ${ }^{262}$ Furthermore, their acinar cells exhibited a higher apoptosis rate. Newborn ferrets have only mild pancreatic pathology of duct dilations with inspissated secretions (Table 1). Juvenile and adult CF ferrets develop more severe pancreatic pathology, which is similar to CF patients, but $15 \%$ of the animals retain predominantly normal pancreatic histology at the time of death. ${ }^{263}$ This suggests that additional factors may be necessary for the manifestation of the disease. Although CF pigs and ferrets seem to be more useful and promising models compared with mice, the problems with these animals include limited access for most researchers and the severe intestinal phenotypes.

It is known that pancreatic sufficient patients with CF have the greater risk of developing pancreatitis. ${ }^{264,265}$ Not surprisingly, the type of CFTR mutation determines the risk of pancreatitis ${ }^{265}$ : CF patients with mild CFTR genotypes have a greater risk of developing pancreatitis compared with patients with moderatesevere genotypes. Pancreatitis occurred in $20 \%$ of the patients, with a quarter presenting with pancreatitis prior to the diagnosis of CF, typically in late childhood and adulthood. ${ }^{265}$ The majority $(60 \%)$ of affected CF patients experienced recurrent attacks of acute pancreatitis; $18 \%$ had a single episode of acute pancreatitis, and $22 \%$ showed signs of chronic pancreatitis. Furthermore and importantly, patients with pancreatitis received a diagnosis of $\mathrm{CF}$ at a significantly older age and had lower sweat chloride levels than did patients without pancreatitis. ${ }^{265}$

\section{Acute Pancreatitis}

Acute pancreatitis is a sudden inflammation of the pancreas without any reliable treatment. There are several diverse causative factors for pancreatitis, including biliary disease, excessive ethanol intake, and metabolic causes such as hypertriglyceridemia. ${ }^{266-268}$ The severity of acute pancreatitis can vary from mild to severe. ${ }^{269}$ The exact pathomechanism of acute pancreatitis is not well understood; however, animal models provide an opportunity for the investigation of pathophysiological processes and for the development of new therapeutic possibilities. ${ }^{270}$ Almost all types of acute pancreatitis seem to share a common mechanism of abnormal inhibition of pancreatic zymogen secretion and premature activation of these digestive enzymes. ${ }^{271}$ In addition or alternatively, stressors inducing pancreatitis can also activate nuclear factor $\mathrm{kB},{ }^{272}$ a transcription factor responsible for regulating the expression of numerous proinflammatory mediators.
Although acute pancreatitis has long been considered as a disease of the acinar cells, recent evidence has proved the role of pancreatic ducts in the pathogenesis of the disease. In fact, they may be primary targets of toxic factors. Bile acids and ethanol dose dependently affect pancreatic ductal $\mathrm{HCO}_{3}^{-}$and fluid secretion (Figs. 3 and 4). ${ }^{273-275}$ When nonconjugated bile acids are administered luminally to isolated guinea pig ductal cells in low concentration $(100 \mu \mathrm{M})$, they activate luminal $\mathrm{Cl}^{-} / \mathrm{HCO}_{3}^{-}$exchange activity and thus stimulate $\mathrm{HCO}_{3}^{-}$secretion via inducing oscillatory elevation of intracellular $\mathrm{Ca}^{2+}$ concentration (Fig. 3A). ${ }^{274}$ This stimulatory effect of chenodeoxycholate was also confirmed in human CFPAC-1 cell line and was shown to be dependent on CFTR expression, but not CFTR $\mathrm{Cl}^{-}$channel activity. ${ }^{276}$ We believe that the stimulation of pancreatic secretion may serve as a defense mechanism of ductal cells, so toxic bile acids are washed out from the ductal tree to protect acinar cells. If this process is inefficient, bile acids will reach the ductal cells in high concentration and cause sustained (eventually toxic) elevation of intracellular $\mathrm{Ca}^{2+}$ signaling, damage the mitochondria, deplete intracellular ATP levels, and consequently block basolateral and apical ion transport mechanisms (Fig. 3B). ${ }^{36,273,274,277}$ The results of the authors' recent preliminary experiments have suggested that there is also reduction of pancreatic ductal $\mathrm{HCO}_{3}^{-}$ secretion in patients with biliary acute pancreatitis. ${ }^{278}$ Intraductal $\mathrm{pH}$ was significantly lower in these patients versus control subjects.

One of the most common causes of acute pancreatitis is excessive ethanol consumption. Interestingly, ethanol administration itself does not induce experimental acute pancreatitis in rodents. ${ }^{279,280}$ Ethanol exerts only modest effects on acinar cell $\mathrm{Ca}^{2+}$ homeostasis, even in very high concentrations, whereas a combination of alcohol and fatty acids causes massive intracellular $\mathrm{Ca}^{2+}$ release and intracellular trypsinogen activation. ${ }^{279-283}$ There are fewer data available concerning the effects of ethanol and their metabolites on pancreatic ductal cells. Similarly to nonconjugated bile acids, ethanol has a dual effect on pancreatic $\mathrm{HCO}_{3}^{-}$secretion. Yamamoto et $\mathrm{al}^{275}$ showed that ethanol in low concentration augments the stimulatory effect of secretin (Fig. 4A), whereas in high concentration, it inhibits the secretory rate (Fig. 4B). This dual effect may be partly mediated by CFTR. Electrophysiological studies on native guinea pig pancreatic ductal cells showed that 10 and $100 \mathrm{mM}$ ethanol increases basal, but reversibly blocks, forskolin-stimulated CFTR currents via depletion of $\mathrm{ATP}_{\mathrm{i} .}{ }^{284}$

There is evidence that the premature activation of trypsinogen to trypsin inside the acinar cell ${ }^{285,286}$ or in the ductal lumen $^{287,288}$ is a key event in the development of pancreatitis. A number of publications proved that trypsin activates enzyme secretion from acinar cells via proteinase-activated receptor 2 (PAR-2), ${ }^{289,290}$ but the effect of trypsin on PDECs is somewhat different depending on the species and also on the localization of PAR-2 (Fig. 5). Nguyen et $\mathrm{al}^{291}$ suggest that trypsin activates CFTR and $\mathrm{Ca}^{2+}$-activated $\mathrm{Cl}^{-}$channel in dog PDECs and stimulates $\mathrm{HCO}_{3}^{-}$secretion in the CAPAN-1 human pancreatic adenocarcinoma cell line. ${ }^{167}$ In contrast, $\mathrm{HCO}_{3}^{-}$efflux is inhibited by trypsin in a dose-dependent manner in bovine PDECs. ${ }^{292}$ We demonstrated that PAR-2 activation by trypsin inhibits both the SLC26 anion exchanger(s) and CFTR $\mathrm{Cl}^{-}$channel in guinea pig PDECs. ${ }^{293}$ Trypsin stimulates $\mathrm{HCO}_{3}^{-}$secretion via PAR-2 activation, when the receptor is localized to the basolateral membrane. ${ }^{167,291}$ In contrast, the effect is inhibition when the receptor is localized to the luminal membrane. ${ }^{292,293}$

The role of PAR-2 in experimental acute pancreatitis is controversial and is greatly dependent on the utilized disease model. Numerous studies have confirmed that PAR-2 has a 


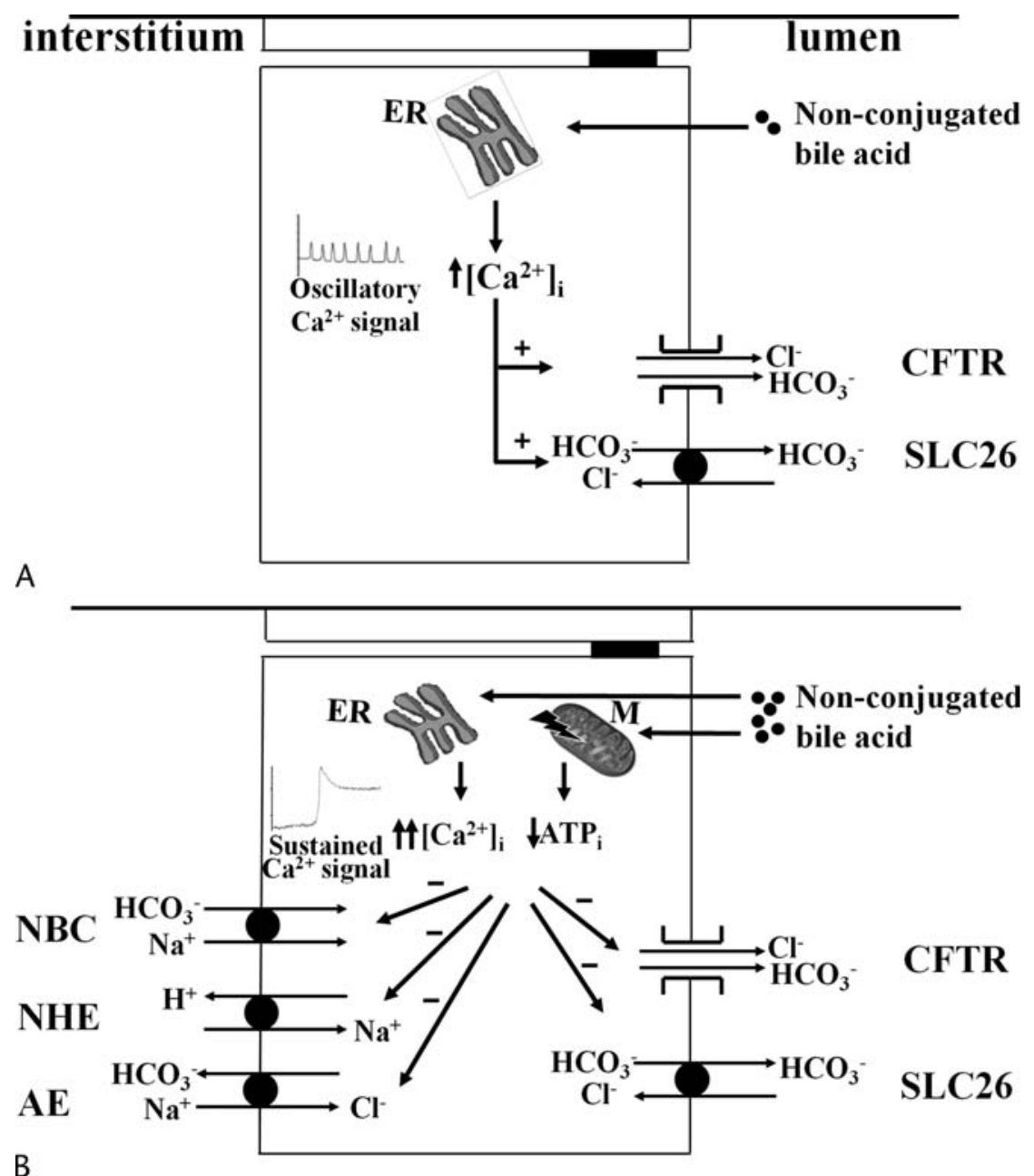

FIGURE 3. Effects of nonconjugated bile acids on pancreatic ductal $\mathrm{HCO}_{3}^{-}$secretion. Bile acids may enter the pancreatic duct in case of distal biliary obstruction. A, Low doses of bile acids induce dose-dependent $\mathrm{Ca}^{2+}$ release from intracellular $\mathrm{Ca}^{2+}$ stores, and stimulate $\mathrm{HCO}_{3}^{-}$ secretion via activation of luminal $\mathrm{Cl}^{-} / \mathrm{HCO}_{3}^{-}$exchanger. $\mathrm{B}$, High concentration of bile acids induce a toxic, sustained [Ca $\left.{ }^{2+}\right]_{i}$ elevation and ATPi depletion, which inhibit the acid-base transporters on the basolateral and luminal membrane of ductal cells. ER, endoplasmic reticulum; $\mathrm{M}$, mitochondrion; +, stimulation; -, inhibition.

protective role in secretagogue-induced pancreatitis in mice ${ }^{294-296}$ and rats. ${ }^{297}$ Based on results obtained in transgenic mice, Singh et $\mathrm{al}^{290}$ have hypothesized that PAR-2 activation may decrease secretagogue-induced pancreatic damage by promoting zymogen secretion from acinar cells. Namkung et al ${ }^{298}$ demonstrated that down-regulation of MAP kinase signaling pathway may be involved in the protective effects of PAR-2 activation. However, in contrast to that found in the cerulein-induced acute pancreatitis model, deletion or pharmacological inhibition of PAR-2 markedly reduced the severity of pancreatitis evoked by intraductal infusion of taurocholate in mice, ${ }^{295,299}$ which implies a detrimental role of this receptor. The previously mentioned discrepancies may be due to differential local and systemic effects of PAR-2 activation. ${ }^{297}$ Interestingly, we have demonstrated that PAR-2 is also localized to the apical membrane of human and guinea pig PDECs. Furthermore, PAR-2 activation reduced pancreatic ductal $\mathrm{HCO}_{3}^{-}$secretion by inhibition of the apical anion exchanger and CFTR. ${ }^{293}$ The reduction in ductal secretion can facilitate the development of pancreatitis by decreasing luminal $\mathrm{pH}$ and promoting premature activation of trypsinogen inside the pancreatic ducts.
Recently, it has been demonstrated that smoking is an important risk factor for non-gallstone-related acute pancreatitis. ${ }^{300}$ The risk is even higher in individuals with associated monthly ethanol consumption of $400 \mathrm{~g}$ or greater. The effect of cigarette smoke may be partly mediated by impairment of CFTR function. ${ }^{301-303}$ Clunes et $\mathrm{al}^{304}$ proposed that cigarette smoke exposure rapidly reduces CFTR function by internalizing CFTR protein, leading to airway dehydration. Similar mechanisms of CFTR inhibition are suspected in the pancreas; however, no detailed investigations have been performed in this research field. The detrimental effect of cigarette smoke is potentially caused by the combined effects of several thousand chemicals, and it is difficult to pinpoint individual compounds. Nevertheless, some studies have attempted to investigate the effects of major cigarette components. Nicotine was found to inhibit pancreatic $\mathrm{HCO}_{3}^{-}$secretion in the dog, ${ }^{305}$ but others could not confirm these findings. ${ }^{306}$

Notably, some recent publications have identified the role of CFTR in the pathogenesis of acute pancreatitis, which provide strong evidence for the involvement of pancreatic ducts. DiMagno et $\mathrm{al}^{307,308}$ found that CFTR knockout mice exhibited more severe acute pancreatitis than did wild-type mice. 


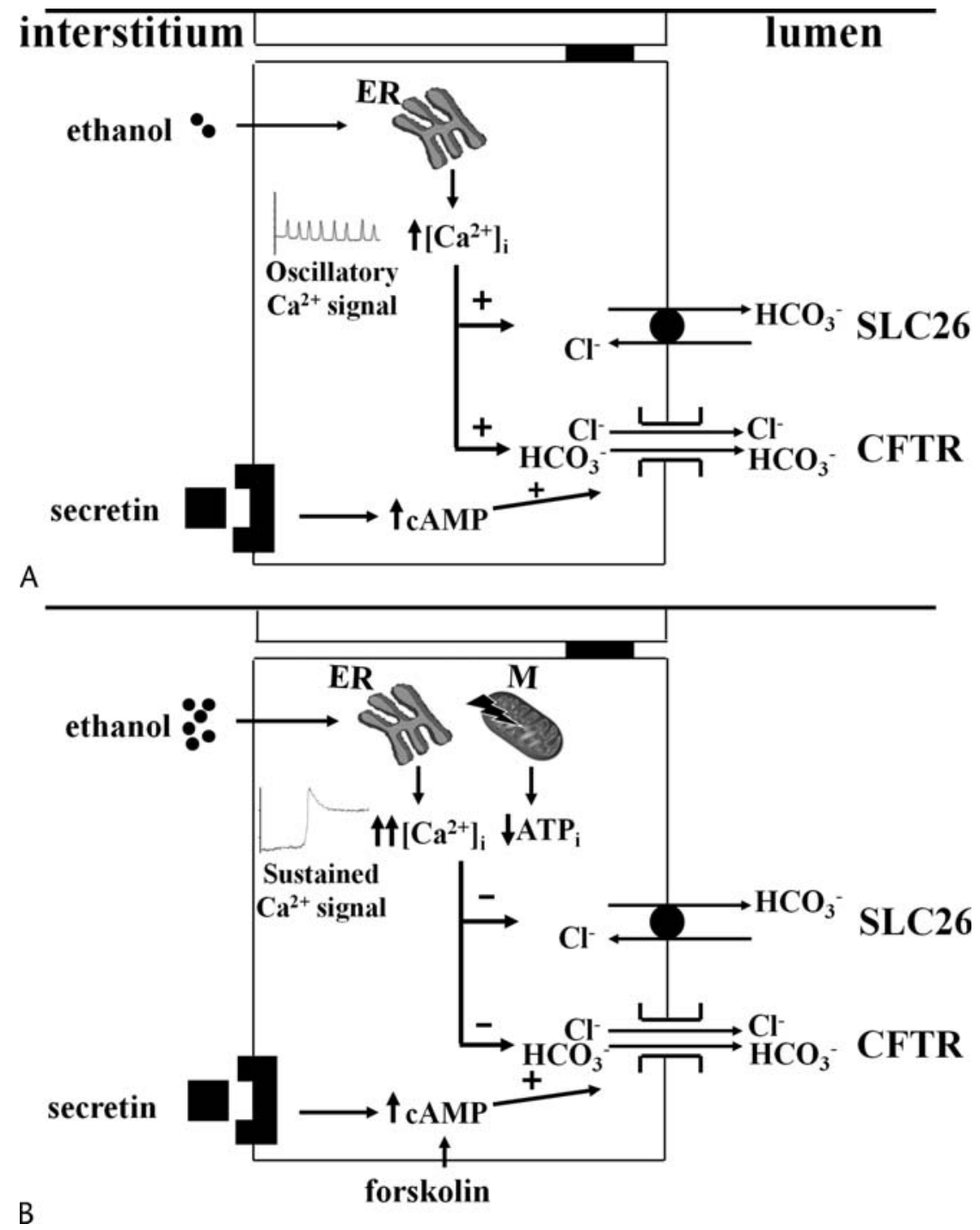

FIGURE 4. Effects of ethanol on pancreatic ductal $\mathrm{HCO}_{3}^{-}$secretion. A, Ethanol and secretin together cause elevation of [Ca $\left.{ }^{2+}\right]_{i}$ and $\mathrm{CAMP}$ level. Ethanol in low concentration enhances secretin-stimulated $\mathrm{HCO}_{3}^{-}$secretion. B, Ethanol in high concentration inhibits secretin- and forskolin- stimulated $\mathrm{HCO}_{3}^{-}$secretion by releasing $\mathrm{Ca}^{2+}{ }_{\mathrm{i}}$ and depletion of $\mathrm{ATP}{ }_{\mathrm{i}}$. ER, endoplasmic reticulum; $\mathrm{M}$, mitochondrion; - , inhibition; + , stimulation.

However, CFTR knockout animals are also characterized by exuberant pancreatic inflammation, impaired acinar apoptosis, and mild pancreatic insufficiency, ${ }^{307,308}$ which could potentially confound the obtained results. Furthermore, only the secretagogue-induced acute pancreatitis model was tested, so model-specific effects cannot be excluded. Recently, we have demonstrated that NHERF-1 knockout mice, which have markedly lower pancreatic ductal $\mathrm{HCO}_{3}^{-}$and fluid secretory rates due to a reduction of apical CFTR expression, also show signs of more severe acute pancreatitis in 2 disease models versus wild-type mice. ${ }^{25}$ Furthermore, Cavestro et $\mathrm{al}^{309}$ identified statistically significant association of CFTR mutations with acute recurrent pancreatitis, which may be due to insufficient pancreatic electrolyte and fluid secretion. ${ }^{310}$

\section{Chronic Pancreatitis}

Chronic pancreatitis is a progressive inflammatory disorder that leads to irreversible destruction of the pancreas.
Pancreatic damage may result from repeated attacks of acute pancreatitis, ${ }^{311,312}$ but some doubt that this is in fact the case. On histology, the defining triad of chronic pancreatitis (irrespective of the cause or location) is acinar loss, mononuclear cell infiltration, and interlobular/intralobular/periductal fibrosis. ${ }^{313}$ The inflammatory milieu also leads to alteration of endocrine functions. ${ }^{314}$ Overall, these changes eventually lead to exocrine and endocrine pancreatic insufficiency, which manifest in steatorrhea, malnutrition, and type $3 \mathrm{c}$ diabetes mellitus.

The pancreatic ductal tree is affected both morphologically and functionally in chronic pancreatitis. These changes are essential in the diagnosis of the disease and can be nicely followed by pancreatic imaging and function tests. Ducts become dilated with concretions, and the epithelium shows signs of atrophy or hyperplasia or undergoes squamous metaplasia. It is no wonder that chronic pancreatitis greatly increases the risk of pancreatic ductal adenocarcinoma. ${ }^{315}$ It has long been known that age at diagnosis, smoking, and drinking are major predictors of progression and 


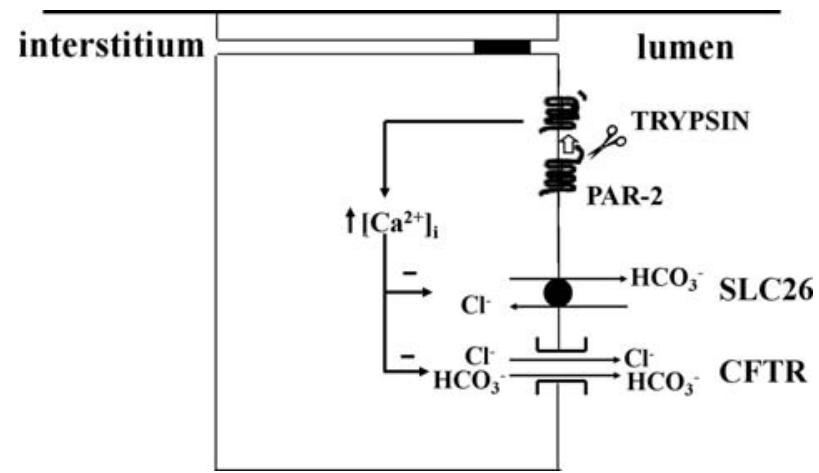

FIGURE 5. The effect of trypsin on pancreatic ductal epithelial cells. Trypsinogen can be prematurely activated to trypsin inside the ductal lumen during pancreatitis. Consequently, trypsin induces dose-dependent $\left[\mathrm{Ca}^{2+}\right]_{i}$ elevation from intracellular $\mathrm{Ca}^{2+}$ stores via activation of protease-activated receptor 2 . This causes reduction of ductal $\mathrm{HCO}_{3}^{-}$secretion by ductal cells via inhibition of luminal $\mathrm{Cl}^{-} / \mathrm{HCO}_{3}^{-}$exchangers and $\mathrm{CFTR} \mathrm{Cl}$ - channel; -, inhibition.

mortality of patients with chronic pancreatitis. ${ }^{316,317}$ In fact, the detrimental effect of smoking on pancreatitis may be at least partly due to alteration of pancreatic ductal function. An interesting study by Kadiyala et $\mathrm{al}^{318}$ showed that $\mathrm{HCO}_{3}^{-}$concentration of pancreatic fluid in smokers is significantly reduced (indicating decreased ductal function) compared with nonsmokers. The consequent reduction of ductal luminal $\mathrm{pH}$, fluid secretion, and increased pancreatic protein secretion lead to protein plug and stone formation.

Pancreatic function tests can be used to determine the reserve of the pancreas in the clinical setting, although quite often these are not readily available. Most tests (eg, fecal elastase, fecal fat quantification, Lundh, and the ${ }^{13} \mathrm{C}$-mixed triglycerides breath tests) are used to evaluate the acinar reserve, whereas the secretin test is used to measure secretory volume and $\mathrm{HCO}_{3}^{-}$flow. ${ }^{319}$ Nevertheless, pancreatic function/reserve can also be roughly estimated based on imaging such as endoscopic retrograde pancreatography, computed tomography, endoscopic ultrasound, and secretin-enhanced magnetic resonance cholangiopancreatography (MRCP) ${ }^{320}$ Magnetic resonance cholangiopancreatography has a fundamental role in visualization of the hepatobiliary ductal system. The technique is commonly performed with heavily T2weighted sequences to highlight static or slow-moving fluids. ${ }^{321}$ In the last 15 to 20 years, stimulation of pancreatic and biliary secretion by intravenous administration of secretin has been utilized for enhancing MRCP. ${ }^{322}$ This allows the radiologist to better visualize the ductal system compared with MRCP without secretin stimulation. The diagnostic potential of secretin-enhanced MRCP is equivalent to the more conventional endoscopic retrograde cholangiopancreatography. ${ }^{323}$ Secretin-enhanced MRCP allows us to noninvasively estimate the pancreatic secretory volume and thus can be useful for quantification of exocrine function. ${ }^{324}$ The advantage of secretin-enhanced MRCP versus endoscopic retrograde cholangiopancreatography is that the former has no risk of iatrogenic acute pancreatitis. Indications of this technique include the detection and characterization of pancreatic ductal anomalies and strictures, evaluation of the integrity of the pancreatic duct, characterization of any communication between the pancreatic duct and pseudocysts/pancreatic fistulas, and the assessment of pancreatic function and sphincter of Oddi dysfunction. ${ }^{321}$ Although reduction of $\mathrm{HCO}_{3}^{-}$secretion is 1 of the earliest features of chronic pancreatitis, the availability and price of secretin limit the use of this gastrointestinal hormone for functional and imaging tests.
Autoimmune pancreatitis is a rare disease of the pancreas that can be cured by administration of steroids. ${ }^{325,326}$ Ito et $\mathrm{al}^{327}$ found that 11 of 12 patients with autoimmune pancreatitis showed reduction in pancreatic volume and amylase output, whereas reduction in $\mathrm{HCO}_{3}^{-}$secretion was observed in only 5 of 12 patients. An elegant study by Ko et $\mathrm{al}^{328}$ confirmed the role of pancreatic ducts in this unique form of pancreatitis. They showed that mislocalized CFTR inside the cytoplasm of duct cells was a characteristic feature of autoimmune pancreatitis, which was associated with a reduction of secretin-induced pancreatic $\mathrm{HCO}_{3}^{-}$secretion. Because CFTR mislocalization was also detected in a small number of patients with alcoholic pancreatitis and with obstructive pancreatitis, this may be the case in all forms of chronic pancreatitis (although this needs to be confirmed on a larger population of patients). Treatment of autoimmune pancreatitis with corticosteroids not only corrected the localization of CFTR to the apical membrane, but also reversed the impaired $\mathrm{HCO}_{3}^{-}$secretion. Ko et al ${ }^{329}$ have also shown that pancreatic ductal dysfunction in alcoholic chronic pancreatitis does not recover within a year without active anti-inflammatory therapy.

The importance of intracellular $\mathrm{Ca}^{2+}$ signaling in the pathogenesis of chronic pancreatitis is highlighted by the fact that polymorphisms in the $\mathrm{Ca}^{2+}$-sensing receptor gene increase the risk of the disease. ${ }^{330,331}$ The role of CFTR in the pathogenesis of idiopathic pancreatitis has also been supported by results of genetic studies. ${ }^{332,333}$ The first articles on CFTR mutations linked to a higher frequency of the disease were published in the New England Journal of Medicine, ${ }^{334,335}$ but these findings have been confirmed by numerous other investigators. Although 2 copies of severe CFTR mutations lead to CF, combinations of a severe CFTR mutation and a mild CFTR mutation lead to atypical CF and high pancreatitis risk, a severe $C F T R$ mutation combined with pancreas divisum or SPINK1 mutation can result in increased susceptibility to sporadic chronic pancreatitis. ${ }^{336}$ Furthermore, it has recently been demonstrated that functional CFTR variants with impaired $\mathrm{HCO}_{3}^{-}$(but not $\mathrm{Cl}^{-}$) permeability increase the risk of pancreatitis but not for $\mathrm{CF}^{38,337}$

\section{Diabetes Mellitus}

There is close interaction of the exocrine and endocrine pancreatic parenchyma, ${ }^{338}$ so it is not surprising that ductal function is affected in diabetes mellitus, and vice versa, alteration of ductal function can also contribute to the development of diabetes. In fact, it is well known that a number of pancreatic diseases (CF, pancreatitis, and pancreatic adenocarcinoma) can cause diabetes, which always has to be kept in mind.

Many animal and human studies have demonstrated reduced pancreatic exocrine secretion (including total secretory volume pancreatic enzyme activity and $\mathrm{HCO}_{3}^{-}$concentration) in both insulin-dependent and non-insulin-dependent diabetes mellitus, but the clinical relevance of these findings remains uncertain. ${ }^{338,339}$ Secretin-stimulated pancreatic secretion including volume and $\mathrm{HCO}_{3}^{-}$output was decreased in patients with insulindependent ${ }^{340,341}$ and non-insulin-dependent diabetes mellitus ${ }^{342}$ when compared with control subjects. The prevalence of exocrine insufficiency (which is usually mild to moderate, without clinical signs of exocrine pancreatic insufficiency) is somewhat lower in non-insulin-dependent $(30 \%-50 \%)$ versus insulin-dependent $(50 \%)$ diabetes mellitus, ${ }^{339}$ although in certain subgroups of patients, this rate may be much higher. ${ }^{343}$ Exocrine insufficiency seems to be correlated to the early onset of endocrine failure, long-lasting diabetes mellitus, and low body mass index levels. ${ }^{344}$

So how is pancreatic ductal secretion affected in diabetes mellitus? Importantly, diabetes inevitably causes imbalance of islet cell hormone levels. Given the stimulatory effect of 
endogenous insulin on ductal secretion, one would expect to find decreased rates of secretion due to abnormal insulin secretion and/or insulin resistance. Indeed, this is actually the case, but not in all patients, so the involvement of other factors is likely. Nevertheless, insulin may be a vital trophic factor for not only acinar, but also for ductal cells. The reduced ductal secretion may be partly due to morphological alterations of the pancreas in patients with diabetes, such as smaller tissue size (atrophy), especially in insulin-dependent cases. ${ }^{345}$ Furthermore, duct morphology on endoscopic retrograde cholangiopancreatography in patients with diabetes is similar to the changes observed in chronic pancreatitis. ${ }^{346,347}$ Autoantibodies (eg, against carbonic anhydrase) found in patients with insulin-dependent diabetes may damage the ducts and cause compromised cellular function. Because ductal secretion is regulated by the nervous system, one cannot exclude the detrimental effects of autonomic neuropathy in diabetes mellitus. ${ }^{339}$ In addition, high glucose concentrations were found to inhibit rat pancreatic interlobular ductal $\mathrm{HCO}_{3}^{-}$secretion. ${ }^{348}$ To explain the mechanism of reduced secretion, the authors hypothesized that glucose enters the cell via the sodium-dependent glucose transporter, and the consequent increase in $\left[\mathrm{Na}^{+}\right]_{\mathrm{i}}$ causes depolarization, which will reduce the driving force for $\mathrm{HCO}_{3}^{-}$secretion. ${ }^{348}$ Incubation of ducts isolated from streptozotocin-treated diabetic animals in normal glucose solutions reversed the defect in secretion. Another possible explanation of decreased ductal secretion was proposed by Hootman et al. ${ }^{349}$ The increases in cyclic AMP levels evoked by exposure to secretin were not significantly different in pancreatic ducts isolated from healthy and diabetic guinea pigs, nor were levels of CFTR or $\mathrm{Na}^{+} / \mathrm{K}^{+}$-ATPase expression. ${ }^{349}$ However, $\mathrm{Na}^{+} /$ $\mathrm{K}^{+}$-ATPase activity in pancreatic ducts isolated from diabetic animals was markedly decreased, suggesting a change in the enzyme's catalytic properties in the diabetic tissues. Notably, in a vicious cycle, reduced ductal secretion can also lead to a further impairment of exocrine pancreatic function in diabetic conditions.

\section{CONCLUSIONS AND FUTURE DIRECTIONS}

It is without a doubt that the most important ion in terms of pancreatic ductal secretion is $\mathrm{HCO}_{3}^{-}$. The majority of pancreatic fluid originates from duct cells; secretion is mediated via paracellular and transcellular pathways. We have learned much in recent decades about the mechanism and regulation of pancreatic ductal $\mathrm{HCO}_{3}^{-}$and fluid secretion, yet our knowledge is still incomplete. Without a doubt, secretion is mediated by a complex interaction of different transporters. The most important transporters involved in ductal secretion have been identified; however, it is still unclear how the luminal $140 \mathrm{mM} \mathrm{HCO}_{3}^{-}$ concentration is reached during stimulated conditions in humans. There is ample evidence that CFTR has a central role in pancreatic ductal $\mathrm{HCO}_{3}^{-}$and fluid secretion. Cystic fibrosis transmembrane conductance regulator not only conducts anions such as $\mathrm{Cl}^{-}$and $\mathrm{HCO}_{3}^{-}$, but it also interacts with numerous transporters involved in secretion. Studying the distribution and interaction of transporters in/within different segments of the ductal tree may shed further light on the exact mechanism of $\mathrm{HCO}_{3}^{-}$ secretion.

The localization and function of CFTR are also affected by severe diseases such as $\mathrm{CF}$ and pancreatitis. The resulting alterations of pancreatic $\mathrm{HCO}_{3}^{-}$and fluid secretion are characteristic features of these diseases. Cystic fibrosis causes a marked reduction in ductal secretion, eventually leading to the destruction of the gland. The utilization of newly developed pig and ferret $\mathrm{CF}$ models (which better mimic the human disease compared with rodents) will help us in better understanding the disease.
However, for most researchers, these models remain inaccessible. Possible therapeutic targets in restoring defective ductal secretion in $\mathrm{CF}$ include the $\mathrm{Ca}^{2+}$-activated $\mathrm{Cl}^{-}$channels and the restoration of CFTR activity by correctors, potentiators, and gene transfer. Pancreatitis-inducing agents (such as bile acids and ethanol) have a dose-dependent effect on ductal secretion; low concentrations stimulate secretion, whereas high concentrations inhibit secretion. The modulation of ductal secretion may have beneficial effects in the prevention and/or treatment of pancreatitis that is thought to be primarily a disease of the acinar cells.

Despite some marked differences between pancreatic acinar and ductal cells, they both seem to be damaged by toxic factors in a similar way. Therefore, therapeutic options are likely to help acinar and ductal cells. In fact, we have quite a few therapeutic targets such as intracellular ATP depletion and toxic $\mathrm{Ca}^{2+}$ signaling that need to be investigated further and taken from the bench to bedside. For example, the latter is already on its way, by testing the effect of the "Ca ${ }^{2+}$ antagonist" $\mathrm{MgSO}_{4}$ in the prevention of post-endoscopic retrograde cholangiopancreatography pancreatitis. ${ }^{350}$ More such randomized clinical trials are desperately needed in evaluating treatments of pancreatic diseases.

Notably, our current understanding of the physiology and pathophysiology of pancreatic secretion mainly comes from animal studies. As mentioned previously, marked differences exist in the secretory and disease mechanisms of various species. Therefore, the results obtained from animal experiments need to be interpreted with caution and cannot necessarily be directly adapted to the human situation. This is especially true when we take a look at the low number of therapeutic interventions that have made it to clinical practice. Hopefully, the situation will improve by finding/using better disease models.

\section{REFERENCES}

1. Hegyi P, Petersen $\mathrm{OH}$. The exocrine pancreas: the acinar-ductal tango in physiology and pathophysiology. Rev Physiol Biochem Pharmacol. 2013;165:1-30

2. Petersen O. Physiology of acinar cell secretion. In: Beger H, Warshaw A, Büchler M, eds. The Pancreas. 2nd ed. Malden, MA: Blackwell Publishing Ltd; 2008:71-77.

3. Ishiguro H, Yamamoto A, Nakakuki M, et al. Physiology and pathophysiology of bicarbonate secretion by pancreatic duct epithelium. Nagoya J Med Sci. 2012;74:1-18.

4. Lee MG, Muallem S. Physiology of duct cell secretion. In: Beger H, Warshaw A, Büchler M, eds. The Pancreas. 2nd ed. Malden, MA Blackwell Publishing Ltd; 2008:78-90.

5. Steward MC, Ishiguro H, Case RM. Mechanisms of bicarbonate secretion in the pancreatic duct. Annu Rev Physiol. 2005;67:377-409.

6. Lee MG, Ohana E, Park HW, et al. Molecular mechanism of pancreatic and salivary gland fluid and $\mathrm{HCO}_{3}^{-}$secretion. Physiol Rev. 2012;92:39-74.

7. Hegyi P, Maleth J, Venglovecz V, et al. Pancreatic ductal bicarbonate secretion: challenge of the acinar acid load. Front Physiol. 2011;2:36.

8. Case R, Argent BE. Pancreatic duct cell secretion: control and mechanisms of transport. In: Go VLW, DiMagno EP, Gardner JD, et al., eds. The Pancreas: Biology, Pathobiology, and Disease. New York: Raven; 1993:301-350.

9. Wilschanski M, Novak I. The cystic fibrosis of exocrine pancreas. Cold Spring Harb Perspect Med. 2013;3:a009746.

10. Hegyi P, Pandol S, Venglovecz V, et al. The acinar-ductal tango in the pathogenesis of acute pancreatitis. Gut. 2011;60:544-552

11. Argent BE, Gray MA, Steward MC, et al. Cell physiology of pancreatic ducts. In: Johnson LR, Ghishan FK, Kaunitz JD, et al., eds. Physiology of the Gastrointestinal Tract. Oxford: Academic Press; 2012:1399-1424. 
12. Hong JH, Park S, Shcheynikov N, et al. Mechanism and synergism in epithelial fluid and electrolyte secretion. Pflugers Arch. 2014;466: 1487-1499.

13. Novak I, Haanes KA, Wang J. Acid-base transport in pancreas-new challenges. Front Physiol. 2013;4:380.

14. Argent BE, Arkle S, Cullen MJ, et al. Morphological, biochemical and secretory studies on rat pancreatic ducts maintained in tissue culture. QJ Exp Physiol. 1986;71:633-648.

15. Cleveland MH, Sawyer JM, Afelik S, et al. Exocrine ontogenies: on the development of pancreatic acinar, ductal and centroacinar cells. Semin Cell Dev Biol. 2012;23:711-719.

16. Githens S 3rd, Holmquist DR, Whelan JF, et al. Characterization of ducts isolated from the pancreas of the rat. J Cell Biol. 1980;85: $122-135$.

17. Johansen PG, Anderson CM, Hadorn B. Cystic fibrosis of the pancreas. A generalised disturbance of water and electrolyte movement in exocrine tissues. Lancet. 1968;1:455-460.

18. Kerem B, Rommens JM, Buchanan JA, et al. Identification of the cystic fibrosis gene: genetic analysis. Science. 1989;245:1073-1080.

19. Abuladze N, Lee I, Newman D, et al. Molecular cloning, chromosomal localization, tissue distribution, and functional expression of the human pancreatic sodium bicarbonate cotransporter. J Biol Chem. 1998;273: 17689-17695.

20. Dorwart MR, Shcheynikov N, Yang D, et al. The solute carrier 26 family of proteins in epithelial ion transport. Physiology (Bethesda). 2008;23: 104-114.

21. Ohana E, Yang D, Shcheynikov N, et al. Diverse transport modes by the solute carrier 26 family of anion transporters. J Physiol. 2009;587: 2179-2185.

22. Dyck WP, Hightower NC, Janowitz HD. Effect of acetazolamide on human pancreatic secretion. Gastroenterology. 1972;62:547-552.

23. Ko SB, Zeng W, Dorwart MR, et al. Gating of CFTR by the STAS domain of SLC26 transporters. Nat Cell Biol. 2004;6:343-350.

24. Riordan JR, Rommens JM, Kerem B, et al. Identification of the cystic fibrosis gene: cloning and characterization of complementary DNA. Science. 1989;245:1066-1073.

25. Rommens JM, Iannuzzi MC, Kerem B, et al. Identification of the cystic fibrosis gene: chromosome walking and jumping. Science. 1989;245: 1059-1065.

26. Deeley RG, Westlake C, Cole SP. Transmembrane transport of endo- and xenobiotics by mammalian ATP-binding cassette multidrug resistance proteins. Physiol Rev. 2006;86:849-899.

27. Riordan JR. Assembly of functional CFTR chloride channels. Annu Rev Physiol. 2005;67:701-718.

28. Guggino WB, Stanton BA. New insights into cystic fibrosis: molecular switches that regulate CFTR. Nat Rev Mol Cell Biol. 2006;7:426-436.

29. Shenolikar S, Voltz JW, Cunningham R, et al. Regulation of ion transport by the NHERF family of PDZ proteins. Physiology (Bethesda) 2004;19:362-369.

30. Gray MA, Pollard CE, Harris A, et al. Anion selectivity and block of the small-conductance chloride channel on pancreatic duct cells. Am J Physiol. 1990;259:C752-C761.

31. Gray MA, O'Reilly C, Winpenny J, et al. Functional interactions of $\mathrm{HCO}_{3}^{-}$with cystic fibrosis transmembrane conductance regulator. JOP. 2001;2:207-211

32. Shcheynikov N, Kim KH, Kim KM, et al. Dynamic control of cystic fibrosis transmembrane conductance regulator $\mathrm{Cl}^{-} / \mathrm{HCO}_{3}^{-}$selectivity by external $\mathrm{Cl}^{-}$. J Biol Chem. 2004;279:21857-21865.

33. Ishiguro $\mathrm{H}$, Steward MC, Naruse $\mathrm{S}$, et al. CFTR functions as a bicarbonate channel in pancreatic duct cells. J Gen Physiol. 2009; $133: 315-326$
34. Park HW, Nam JH, Kim JY, et al. Dynamic regulation of CFTR bicarbonate permeability by $\left[\mathrm{Cl}^{-}\right]_{\mathrm{i}}$ and its role in pancreatic bicarbonate secretion. Gastroenterology. 2010;139:620-631.

35. O'Reilly CM, Winpenny JP, Argent BE, et al. Cystic fibrosis transmembrane conductance regulator currents in guinea pig pancreatic duct cells: inhibition by bicarbonate ions. Gastroenterology. 2000;118: 1187-1196.

36. Maleth J, Hegyi P. Calcium signaling in pancreatic ductal epithelial cells: an old friend and a nasty enemy. Cell Calcium. 2014; 55:337-345

37. Park S, Shcheynikov N, Hong JH, et al. IRBIT mediates synergy between $\mathrm{Ca}^{2+}$ and cAMP signaling pathways during epithelial transport in mice. Gastroenterology. 2013;145:232-241.

38. LaRusch J, Jung J, General IJ, et al. Mechanisms of CFTR functional variants that impair regulated bicarbonate permeation and increase risk for pancreatitis but not for cystic fibrosis. PLoS Genet. 2014; 10:e1004376.

39. Choi JY, Muallem D, Kiselyov K, et al. Aberrant CFTR-dependent $\mathrm{HCO}_{3}^{-}$transport in mutations associated with cystic fibrosis. Nature. 2001:410:94-97.

40. Ahn W, Kim KH, Lee JA, et al. Regulatory interaction between the cystic fibrosis transmembrane conductance regulator and $\mathrm{HCO}_{3}^{-}$salvage mechanisms in model systems and the mouse pancreatic duct. J Biol Chem. 2001;276:17236-17243.

41. Kunzelmann K. CFTR: interacting with everything? News Physiol Sci. 2001;16:167-170.

42. Ko SB, Shcheynikov N, Choi JY, et al. A molecular mechanism for aberrant CFTR-dependent $\mathrm{HCO}_{3}^{-}$transport in cystic fibrosis. EMBO J 2002;21:5662-5672.

43. Brone B, Eggermont J. PDZ proteins retain and regulate membrane transporters in polarized epithelial cell membranes. Am J Physiol Cell Physiol. 2005;288:C20-C29.

44. Guggino WB. The cystic fibrosis transmembrane regulator forms macromolecular complexes with PDZ domain scaffold proteins. Proc Am Thorac Soc. 2004;1:28-32.

45. Li C, Naren AP. Macromolecular complexes of cystic fibrosis transmembrane conductance regulator and its interacting partners. Pharmacol Ther. 2005;108:208-223.

46. Wang Y, Soyombo AA, Shcheynikov N, et al. Slc26a6 regulates CFTR activity in vivo to determine pancreatic duct $\mathrm{HCO}_{3}^{-}$secretion: relevance to cystic fibrosis. EMBO J. 2006;25:5049-5057.

47. Alper SL. Molecular physiology and genetics of $\mathrm{Na}^{+}$-independent SLC4 anion exchangers. $J$ Exp Biol. 2009;212:1672-1683.

48. Ishiguro H, Namkung W, Yamamoto A, et al. Effect of Slc26a6 deletion on apical $\mathrm{Cl}^{-} / \mathrm{HCO}_{3}^{-}$exchanger activity and cAMP-stimulated bicarbonate secretion in pancreatic duct. Am J Physiol Gastrointest Liver Physiol. 2007;292:G447-G455

49. Rakonczay Z Jr, Fearn A, Hegyi $\mathrm{P}$, et al. Characterization of $\mathrm{H}^{+}$and $\mathrm{HCO}_{3}^{-}$transporters in CFPAC-1 human pancreatic duct cells. World $J$ Gastroenterol. 2006;12:885-895.

50. Rakonczay Z Jr, Hegyi P, Hasegawa M, et al. CFTR gene transfer to human cystic fibrosis pancreatic duct cells using a Sendai virus vector. J Cell Physiol. 2008;214:442-455.

51. Ishiguro H, Naruse S, Kitagawa M, et al. Chloride transport in microperfused interlobular ducts isolated from guinea-pig pancreas. J Physiol. 2002;539:175-189.

52. Mount DB, Romero MF. The SLC26 gene family of multifunctional anion exchangers. Pflugers Arch. 2004;447:710-721.

53. Aravind L, Koonin EV. The STAS domain - a link between anion transporters and antisigma-factor antagonists. Curr Biol. 2000;10: R53-R55. 
54. Xie Q, Welch R, Mercado A, et al. Molecular characterization of the murine Slc26a6 anion exchanger: functional comparison with Slc26a1. Am J Physiol Renal Physiol. 2002;283:F826-F838.

55. Shcheynikov N, Yang D, Wang Y, et al. The Slc26a4 transporter functions as an electroneutral $\mathrm{Cl}^{-} / \mathrm{I}^{-} / \mathrm{HCO}_{3}^{-}$exchanger: role of Slc $26 \mathrm{a} 4$ and Slc26a6 in $\mathrm{I}^{-}$and $\mathrm{HCO}_{3}^{-}$secretion and in regulation of CFTR in the parotid duct. $J$ Physiol. 2008;586:3813-3824.

56. Rybalchenko V, Santos-Sacchi J. Anion control of voltage sensing by the motor protein prestin in outer hair cells. Biophys J. 2008;95: 4439-4447.

57. Kim KH, Shcheynikov N, Wang Y, et al. SLC26A7 is a $\mathrm{Cl}^{-}$channel regulated by intracellular pH. J Biol Chem. 2005;280:6463-6470.

58. Dorwart MR, Shcheynikov N, Wang Y, et al. SLC26A9 is a $\mathrm{Cl}^{-}$channel regulated by the WNK kinases. J Physiol. 2007;584:333-345.

59. Rahmati N, Kunzelmann K, Xu J, et al. Slc26a1 1 is prominently expressed in the brain and functions as a chloride channel: expression in Purkinje cells and stimulation of $\mathrm{V} \mathrm{H}^{+}$-ATPase. Pflugers Arch. 2013;465: 1583-1597.

60. Alper SL, Sharma AK. The SLC26 gene family of anion transporters and channels. Mol Aspects Med. 2013;34:494-515.

61. Haila S, Hastbacka J, Bohling T, et al. SLC26A2 (diastrophic dysplasia sulfate transporter) is expressed in developing and mature cartilage but also in other tissues and cell types. J Histochem Cytochem. 2001;49: 973-982.

62. Greeley T, Shumaker H, Wang Z, et al. Downregulated in adenoma and putative anion transporter are regulated by CFTR in cultured pancreatic duct cells. Am J Physiol Gastrointest Liver Physiol. 2001;281: G1301-G1308.

63. Lohi H, Lamprecht G, Markovich D, et al. Isoforms of SLC26A6 mediate anion transport and have functional PDZ interaction domains. Am J Physiol Cell Physiol. 2003;284:C769-C779.

64. Stewart AK, Shmukler BE, Vandorpe DH, et al. SLC26 anion exchangers of guinea pig pancreatic duct: molecular cloning and functional characterization. Am J Physiol Cell Physiol. 2011;301: C289-C303.

65. Schweinfest CW, Henderson KW, Suster S, et al. Identification of a colon mucosa gene that is down-regulated in colon adenomas and adenocarcinomas. Proc Natl Acad Sci US A. 1993;90:4166-4170.

66. Hoglund P, Haila S, Socha J, et al. Mutations of the Down-regulated in adenoma (DRA) gene cause congenital chloride diarrhoea. Nat Genet. 1996; 14:316-319.

67. Moseley RH, Hoglund P, Wu GD, et al. Downregulated in adenoma gene encodes a chloride transporter defective in congenital chloride diarrhea. Am J Physiol. 1999;276:G185-G192.

68. Melvin JE, Park K, Richardson L, et al. Mouse down-regulated in adenoma (DRA) is an intestinal $\mathrm{Cl}^{-} / \mathrm{HCO}_{3}^{-}$exchanger and is up-regulated in colon of mice lacking the $\mathrm{NHE} 3 \mathrm{Na}^{+} / \mathrm{H}^{+}$exchanger. J Biol Chem. 1999; 274:22855-22861.

69. Shcheynikov N, Wang Y, Park M, et al. Coupling modes and stoichiometry of $\mathrm{Cl}^{-} / \mathrm{HCO}_{3}^{-}$exchange by slc26a3 and slc26a6. J Gen Physiol. 2006;127:511-524.

70. Knauf F, Yang CL, Thomson RB, et al. Identification of a chloride-formate exchanger expressed on the brush border membrane of renal proximal tubule cells. Proc Natl Acad Sci U S A. 2001;98: 9425-9430.

71. Tuo B, Riederer B, Wang Z, et al. Involvement of the anion exchanger SLC26A6 in prostaglandin $\mathrm{E}_{2}$ - but not forskolin-stimulated duodenal $\mathrm{HCO}_{3}^{-}$secretion. Gastroenterology. 2006;130:349-358.

72. Clark JS, Vandorpe DH, Chernova MN, et al. Species differences in $\mathrm{Cl}^{-}$affinity and in electrogenicity of SLC26A6-mediated oxalate/Clexchange correlate with the distinct human and mouse susceptibilities to nephrolithiasis. J Physiol. 2008;586:1291-1306.
73. Stewart AK, Yamamoto A, Nakakuki M, et al. Functional coupling of apical $\mathrm{Cl}^{-} / \mathrm{HCO}_{3}^{-}$exchange with $\mathrm{CFTR}$ in stimulated $\mathrm{HCO}_{3}^{-}$secretion by guinea pig interlobular pancreatic duct. Am J Physiol Gastrointest Liver Physiol. 2009;296:G1307-G1317.

74. Boron WF, Boulpaep EL. Intracellular $\mathrm{pH}$ regulation in the renal proximal tubule of the salamander. Basolateral $\mathrm{HCO}_{3}^{-}$transport. J Gen Physiol. 1983;81:53-94.

75. Muallem S, Loessberg PA. Intracellular $\mathrm{pH}$-regulatory mechanisms in pancreatic acinar cells. I. Characterization of $\mathrm{H}^{+}$and $\mathrm{HCO}_{3}^{-}$transporters. J Biol Chem. 1990;265:12806-12812.

76. Zhao H, Star RA, Muallem S. Membrane localization of $\mathrm{H}^{+}$and $\mathrm{HCO}_{3}^{-}$transporters in the rat pancreatic duct. J Gen Physiol. 1994;104:57-85.

77. Ishiguro $\mathrm{H}$, Steward MC, Lindsay AR, et al. Accumulation of intracellular $\mathrm{HCO}_{3}^{-}$by $\mathrm{Na}^{+}-\mathrm{HCO}_{3}^{-}$cotransport in interlobular ducts from guinea-pig pancreas. J Physiol. 1996;495:169-178.

78. Rajendran VM, Oesterlin M, Binder HJ. Sodium uptake across basolateral membrane of rat distal colon. Evidence for $\mathrm{Na}-\mathrm{H}$ exchange and Na-anion cotransport. J Clin Invest. 1991;88:1379-1385.

79. Fitz JG, Persico M, Scharschmidt BF. Electrophysiological evidence for $\mathrm{Na}^{+}$-coupled bicarbonate transport in cultured rat hepatocytes. Am J Physiol. 1989;256:G491-G500.

80. Weintraub WH, Machen TE. $\mathrm{pH}$ regulation in hepatoma cells: roles for Na-H exchange, $\mathrm{Cl}^{-} \mathrm{HCO}_{3}^{-}$exchange, and $\mathrm{Na}^{+}-\mathrm{HCO}_{3}^{-}$cotransport Am J Physiol. 1989;257:G317-G327.

81. Dart C, Vaughan-Jones RD. $\mathrm{Na}^{+}-\mathrm{HCO}_{3}^{-}$symport in the sheep cardiac Purkinje fibre. J Physiol. 1992;451:365-385.

82. Novak I, Pahl C. Effect of secretin and inhibitors of $\mathrm{HCO}_{3}^{-} / \mathrm{H}^{+}$transport on the membrane voltage of rat pancreatic duct cells. Pflugers Arch. 1993; 425:272-279

83. Ishiguro H, Steward MC, Sohma Y, et al. Membrane potential and bicarbonate secretion in isolated interlobular ducts from guinea-pig pancreas. J Gen Physiol. 2002;120:617-628.

84. Gross E, Hawkins K, Abuladze N, et al. The stoichiometry of the electrogenic sodium bicarbonate cotransporter NBC1 is cell-type dependent. J Physiol. 2001;531:597-603.

85. Gross E, Fedotoff O, Pushkin A, et al. Phosphorylation-induced modulation of pNBC1 function: distinct roles for the amino- and carboxy-termini. J Physiol. 2003;549:673-682.

86. Boron WF, Chen L, Parker MD. Modular structure of sodium-coupled bicarbonate transporters. J Exp Biol. 2009;212:1697-1706.

87. Yang D, Shcheynikov N, Zeng W, et al. IRBIT coordinates epithelial fluid and $\mathrm{HCO}_{3}^{-}$secretion by stimulating the transporters $\mathrm{pNBC} 1$ and CFTR in the murine pancreatic duct. J Clin Invest. 2009;119: 193-202

88. Shirakabe K, Priori G, Yamada H, et al. IRBIT, an inositol 1,4,5-trisphosphate receptor-binding protein, specifically binds to and activates pancreas-type $\mathrm{Na}^{+} / \mathrm{HCO}_{3}^{-}$cotransporter 1 (pNBC1). Proc Natl Acad Sci U S A. 2006;103:9542-9547.

89. Majumdar D, Maunsbach AB, Shacka JJ, et al. Localization of electrogenic $\mathrm{Na} /$ bicarbonate cotransporter $\mathrm{NBCe} 1$ variants in rat brain. Neuroscience. 2008;155:818-832.

90. Bevensee MO, Schmitt BM, Choi I, et al. An electrogenic $\mathrm{Na}^{+}-\mathrm{HCO}_{3}^{-}$ cotransporter (NBC) with a novel $\mathrm{COOH}$-terminus, cloned from rat brain. Am J Physiol Cell Physiol. 2000;278:C1200-C1211.

91. Park M, Ko SB, Choi JY, et al. The cystic fibrosis transmembrane conductance regulator interacts with and regulates the activity of the $\mathrm{HCO}_{3}^{-}$salvage transporter human $\mathrm{Na}^{+}-\mathrm{HCO}_{3}^{-}$cotransport isoform 3 . J Biol Chem. 2002;277:50503-50509.

92. Brett CL, Tukaye DN, Mukherjee S, et al. The yeast endosomal $\mathrm{Na}^{+} \mathrm{K}^{+} / \mathrm{H}$ exchanger Nhx1 regulates cellular $\mathrm{pH}$ to control vesicle trafficking. Mol Biol Cell. 2005;16:1396-1405. 
93. Orlowski J, Grinstein S. Diversity of the mammalian sodium/proton exchanger SLC9 gene family. Pflugers Arch. 2004;447: 549-565.

94. Donowitz M, Ming Tse C, Fuster D. SLC9/NHE gene family, a plasma membrane and organellar family of $\mathrm{Na}^{+} / \mathrm{H}^{+}$exchangers. Mol Aspects Med. 2013;34:236-251.

95. Yun $\mathrm{CH}$, Tse $\mathrm{CM}$, Nath $\mathrm{SK}$, et al. Mammalian $\mathrm{Na}^{+} / \mathrm{H}^{+}$exchanger gene family: structure and function studies. Am J Physiol. 1995;269:G1-G11.

96. Veel T, Villanger $\mathrm{O}$, Holthe MR, et al. $\mathrm{Na}^{+}-\mathrm{H}^{+}$exchange is not important for pancreatic $\mathrm{HCO}_{3}^{-}$secretion in the pig. Acta Physiol Scand. 1992;144:239-246.

97. Wizemann V, Schulz I. Influence of amphotericin, amiloride, ionophores, and 2,4-dinitrophenol on the secretion of the isolated cat's pancreas. Pflugers Arch. 1973;339:317-338.

98. Lee MG, Ahn W, Choi JY, et al. $\mathrm{Na}(+)$-dependent transporters mediate $\mathrm{HCO}_{3}^{-}$salvage across the luminal membrane of the main pancreatic duct. $J$ Clin Invest. 2000;105(11):1651-1658.

99. Agre P. Aquaporin water channels (Nobel lecture). Angew Chem Int Ed Engl. 2004;43:4278-4290.

100. Verkman AS. Novel roles of aquaporins revealed by phenotype analysis of knockout mice. Rev Physiol Biochem Pharmacol. 2005; 155:31-55.

101. Verkman AS, Mitra AK. Structure and function of aquaporin water channels. Am J Physiol Renal Physiol. 2000;278:F13-F28.

102. Delporte C. Aquaporins in salivary glands and pancreas. Biochim Biophys Acta. 1840;2014:1524-1532.

103. Burghardt B, Nielsen S, Steward MC. The role of aquaporin water channels in fluid secretion by the exocrine pancreas. J Membr Biol. 2006;210:143-153.

104. Ko SB, Naruse S, Kitagawa M, et al. Aquaporins in rat pancreatic interlobular ducts. Am J Physiol Gastrointest Liver Physiol. 2002;282: G324-G331.

105. Burghardt B, Elkaer ML, Kwon TH, et al. Distribution of aquaporin water channels AQP1 and AQP5 in the ductal system of the human pancreas. Gut. 2003;52:1008-1016.

106. Ko SB, Mizuno N, Yatabe Y, et al. Aquaporin 1 water channel is overexpressed in the plasma membranes of pancreatic ducts in patients with autoimmune pancreatitis. J Med Invest. 2009;56(suppl):318-321.

107. Ko SB, Yamamoto A, Azuma S, et al. Effects of CFTR gene silencing by siRNA or the luminal application of a CFTR activator on fluid secretion from guinea-pig pancreatic duct cells. Biochem Biophys Res Commun. 2011;410:904-909.

108. Baum BJ, Alevizos I, Zheng C, et al. Early responses to adenoviral-mediated transfer of the aquaporin-1 cDNA for radiation-induced salivary hypofunction. Proc Natl Acad Sci U S A. 2012;109:19403-19407.

109. Alvarez BV, Loiselle FB, Supuran CT, et al. Direct extracellular interaction between carbonic anhydrase IV and the human NBC1 sodium/bicarbonate co-transporter. Biochemistry. 2003;42: 12321-12329.

110. Alvarez BV, Vilas GL, Casey JR. Metabolon disruption: a mechanism that regulates bicarbonate transport. EMBO J. 2005;24:2499-2511.

111. Alvarez L, Fanjul M, Carter N, et al. Carbonic anhydrase II associated with plasma membrane in a human pancreatic duct cell line (CAPAN-1). J Histochem Cytochem. 2001;49:1045-1053.

112. Fanjul M, Alvarez L, Hollande E. Expression and subcellular localization of a $35-\mathrm{kDa}$ carbonic anhydrase IV in a human pancreatic ductal cell line (Capan-1). J Histochem Cytochem. 2007;55:783-794.

113. Nishimori I, FujikawaAdachi K, Onishi S, et al. Carbonic anhydrase in human pancreas: hypotheses for the pathophysiological roles of CA isozymes. Ann N Y Acad Sci. 1999;880:5-16.
114. Fanjul M, Salvador C, Alvarez L, et al. Targeting of carbonic anhydrase IV to plasma membranes is altered in cultured human pancreatic duct cells expressing a mutated (deltaF508) CFTR. Eur J Cell Biol. 2002;81: $437-447$.

115. Hollande E, Salvador-Cartier C, Alvarez L, et al. Expression of a wild-type CFTR maintains the integrity of the biosynthetic/secretory pathway in human cystic fibrosis pancreatic duct cells. J Histochem Cytochem. 2005;53:1539-1552.

116. Madden ME, Sarras MP Jr. Distribution of $\mathrm{Na}^{+}, \mathrm{K}^{+}$-ATPase in rat exocrine pancreas as monitored by $\mathrm{K}^{+}$-NPPase cytochemistry and [3H]-ouabain binding: a plasma membrane protein found primarily to be ductal cell associated. J Histochem Cytochem. 1987;35:1365-1374

117. Smith ZD, Caplan MJ, Forbush B 3rd, et al. Monoclonal antibody localization of $\mathrm{Na}^{+}-\mathrm{K}^{+}$-ATPase in the exocrine pancreas and parotid of the dog. Am J Physiol. 1987;253:G99-G109.

118. Hayashi M, Novak I. Molecular basis of potassium channels in pancreatic duct epithelial cells. Channels (Austin). 2013;7:432-441.

119. Venglovecz V, Rakonczay Z Jr, Gray MA, et al. Potassium channels in pancreatic duct epithelial cells: their role, function and pathophysiological relevance. Pflugers Arch. 2015;467:625-640.

120. Gray MA, Greenwell JR, Garton AJ, et al. Regulation of maxi-K channels on pancreatic duct cells by cyclic AMP-dependent phosphorylation. J Membr Biol. 1990;115:203-215.

121. Venglovecz V, Hegyi P, Rakonczay Z Jr, et al. Pathophysiological relevance of apical large-conductance $\mathrm{Ca}^{2+}$-activated potassium channels in pancreatic duct epithelial cells. Gut. 2011;60:361-369.

122. Novak I, Wang J, Henriksen KL, et al. Pancreatic bicarbonate secretion involves two proton pumps. J Biol Chem. 2011;286:280-289.

123. Gray MA, Harris A, Coleman L, et al. Two types of chloride channel on duct cells cultured from human fetal pancreas. Am J Physiol. 1989;257: C240-C251.

124. Gray MA, Winpenny JP, Porteous DJ, et al. CFTR and calcium-activated chloride currents in pancreatic duct cells of a transgenic CF mouse. Am J Physiol. 1994;266:C213-C221.

125. Yang YD, Cho H, Koo JY, et al. TMEM16A confers receptor-activated calcium-dependent chloride conductance. Nature. 2008;455:1210-1215.

126. Wang J, Haanes KA, Novak I. Purinergic regulation of CFTR and $\mathrm{Ca}(2+)$-activated $\mathrm{Cl}^{-}$channels and $\mathrm{K}(+)$ channels in human pancreatic duct epithelium. Am J Physiol Cell Physiol. 2013;304:C673-C684.

127. Bergmann F, Andrulis M, Hartwig W, et al. Discovered on gastrointestinal stromal tumor 1 (DOG1) is expressed in pancreatic centroacinar cells and in solid-pseudopapillary neoplasms - novel evidence for a histogenetic relationship. Hum Pathol. 2011;42:817-823.

128. Jung J, Nam JH, Park HW, et al. Dynamic modulation of ANO1/TMEM16A $\mathrm{HCO}_{3}^{-}$permeability by $\mathrm{Ca}^{2+} /$ calmodulin. Proc Natl Acad Sci U S A. 2013;110:360-365.

129. Marsey LL, Winpenny JP. Bestrophin expression and function in the human pancreatic duct cell line, CFPAC-1. J Physiol. 2009;587: 2211-2224.

130. Gaia E, Andriulli A, Tappero G, et al. Influence of sex and body size on pancreatic bicarbonate and enzyme output. J Clin Gastroenterol. 1984;6:429-433.

131. Vellas B, Balas D, Moreau J, et al. Exocrine pancreatic secretion in the elderly. Int J Pancreatol. 1988;3:497-502.

132. Laugier R, Bernard JP, Berthezene $P$, et al. Changes in pancreatic exocrine secretion with age: pancreatic exocrine secretion does decrease in the elderly. Digestion. 1991;50:202-211.

133. Torigoe T, Ito K, Yamamoto A, et al. Age-related change of the secretory flow of pancreatic juice in the main pancreatic duct: evaluation with cine-dynamic MRCP using spatially selective inversion recovery pulse. AJR Am J Roentgenol. 2014;202:1022-1026. 
134. Pandol SJ. The Exocrine Pancreas. San Rafael, CA: Morgan \& Claypool Life Sciences; 2010.

135. Ahuja M, Jha A, Maleth J, et al. cAMP and $\mathrm{Ca}^{2+}$ signaling in secretory epithelia: crosstalk and synergism. Cell Calcium. 2014;55:385-393.

136. Brooks AM, Grossman MI. Postprandial $\mathrm{pH}$ and neutralizing capacity of the proximal duodenum in dogs. Gastroenterology. 1970;59:85-89.

137. Chey WY, Lee YH, Hendricks JG, et al. Plasma secretin concentrations in fasting and postprandial state in man. Am J Dig Dis. 1978;23:981-988.

138. Osnes M, Hanssen LE, Flaten O, et al. Exocrine pancreatic secretion and immunoreactive secretin (IRS) release after intraduodenal instillation of bile in man. Gut. 1978;19:180-184.

139. Gyr K, Beglinger C, Fried M, et al. Plasma secretin and pancreatic response to various stimulants including a meal. Am J Physiol. 1984;246:G535-G542.

140. You CH, Rominger JM, Chey WY. Potentiation effect of cholecystokinin-octapeptide on pancreatic bicarbonate secretion stimulated by a physiologic dose of secretin in humans. Gastroenterology. 1983;85:40-45.

141. Kohler H, Nustede R, Barthel M, et al. Exocrine pancreatic function in dogs with denervated pancreas. Pancreas. 1987;2:676-683.

142. Grundy D, Hutson D, Scratcherd T. The response of the pancreas of the anaesthetized cat to secretin before, during and after reversible vagal blockade. J Physiol. 1983;342:517-526.

143. Sabbatini ME, D'Alecy L, Lentz SI, et al. Adenylyl cyclase 6 mediates the action of cyclic AMP-dependent secretagogues in mouse pancreatic exocrine cells via protein kinase A pathway activation. J Physiol. 2013;591:3693-3707.

144. de Ondarza J, Hootman SR. Regulation of cyclic AMP levels in guinea pig pancreatic ducts and cultured duct epithelial monolayers. Pancreas. 1995;11:261-270.

145. Folsch UR, Fischer H, Soling HD, et al. Effects of gastrointestinal hormones and carbamylcholine on cAMP accumulation in isolated pancreatic duct fragments from the rat. Digestion. 1980;20:277-292.

146. Ashton N, Argent BE, Green R. Effect of vasoactive intestinal peptide, bombesin and substance $\mathrm{P}$ on fluid secretion by isolated rat pancreatic ducts. J Physiol. 1990;427:471-482.

147. Furuta Y, Hashimoto K, Washizaki M. beta-Adrenoceptor stimulation of exocrine secretion from the rat pancreas. Br J Pharmacol. 1978;62:25-29.

148. Kulaksiz H, Cetin Y. Uroguanylin and guanylate cyclase $\mathrm{C}$ in the human pancreas: expression and mutuality of ligand/receptor localization as indicators of intercellular paracrine signaling pathways. $J$ Endocrinol. 2001;170:267-275.

149. Kulaksiz H, Schmid A, Honscheid M, et al. Guanylin in the human pancreas: a novel luminocrine regulatory pathway of electrolyte secretion via cGMP and CFTR in the ductal system. Histochem Cell Biol. 2001; 115:131-145.

150. Kulaksiz H, Cetin Y. The electrolyte/fluid secretion stimulatory peptides guanylin and uroguanylin and their common functional coupling proteins in the rat pancreas: a correlative study of expression and cell-specific localization. Pancreas. 2002;25:170-175.

151. Garbers DL. Guanylyl cyclase receptors and their endocrine, paracrine, and autocrine ligands. Cell. 1992;71:1-4.

152. Lohmann SM, Vaandrager AB, Smolenski A, et al. Distinct and specific functions of cGMP-dependent protein kinases. Trends Biochem Sci. 1997;22:307-312.

153. Vaandrager AB, Smolenski A, Tilly BC, et al. Membrane targeting of cGMP-dependent protein kinase is required for cystic fibrosis transmembrane conductance regulator $\mathrm{Cl}^{-}$channel activation. Proc Natl Acad Sci U S A. 1998;95:1466-1471.

154. Joo NS, London RM, Kim HD, et al. Regulation of intestinal $\mathrm{Cl}^{-}$and $\mathrm{HCO}_{3}^{-}$secretion by uroguanylin. Am J Physiol. 1998;274:G633-G644.
155. Leung PS. The physiology of a local renin-angiotensin system in the pancreas. J Physiol. 2007;580:31-37.

156. Nguyen TD, Okolo CN, Moody MW. Histamine stimulates ion transport by dog pancreatic duct epithelial cells through $\mathrm{H} 1$ receptors Am J Physiol. 1998;275:G76-G84.

157. Ashton N, Evans RL, Elliott AC, et al. Regulation of fluid secretion and intracellular messengers in isolated rat pancreatic ducts by acetylcholine. J Physiol. 1993;471:549-562.

158. Szalmay G, Varga G, Kajiyama F, et al. Bicarbonate and fluid secretion evoked by cholecystokinin, bombesin and acetylcholine in isolated guinea-pig pancreatic ducts. J Physiol. 2001;535:795-807.

159. Bruce JI, Yang X, Ferguson CJ, et al. Molecular and functional identification of $\mathrm{a} \mathrm{Ca}^{2+}$ (polyvalent cation)-sensing receptor in rat pancreas. J Biol Chem. 1999;274:20561-20568.

160. Racz GZ, Kittel A, Riccardi D, et al. Extracellular calcium sensing receptor in human pancreatic cells. Gut. 2002;51:705-711.

161. Hootman SR, Zukerman J, Kovalcik SA. Muscarinic receptors in isolated guinea pig pancreatic ducts. Biochem Pharmacol. 1993;46:291-296.

162. Evans RL, Ashton N, Elliott AC, et al. Interactions between secretin and acetylcholine in the regulation of fluid secretion by isolated rat pancreatic ducts. J Physiol. 1996;496:265-273

163. Khakh BS, North RA. P2X receptors as cell-surface ATP sensors in health and disease. Nature. 2006;442:527-532.

164. Burnstock G, Novak I. Purinergic signalling in the pancreas in health and disease. J Endocrinol. 2012;213:123-141.

165. Novak I. Purinergic receptors in the endocrine and exocrine pancreas. Purinergic Signal. 2008;4:237-253.

166. Ishiguro $\mathrm{H}$, Naruse $\mathrm{S}$, Kitagawa $\mathrm{M}$, et al. Luminal ATP stimulates fluid and $\mathrm{HCO}_{3}^{-}$secretion in guinea-pig pancreatic duct. $J$ Physiol. 1999;519:551-558.

167. Namkung W, Lee JA, Ahn W, et al. $\mathrm{Ca}^{2+}$ activates cystic fibrosis transmembrane conductance regulator- and $\mathrm{Cl}^{-}$-dependent $\mathrm{HCO}_{3}^{-}$ transport in pancreatic duct cells. $J$ Biol Chem. 2003;278:200-207.

168. Szücs A, Demeter I, Burghardt B, et al. Vectorial bicarbonate transport by Capan-1 cells: a model for human pancreatic ductal secretion. Cell Physiol Biochem. 2006;18:253-264.

169. North RA. Molecular physiology of P2X receptors. Physiol Rev. 2002;82:1013-1067.

170. Chan HC, Law SH, Leung PS, et al. Angiotensin II receptor type I-regulated anion secretion in cystic fibrosis pancreatic duct cells. J Membr Biol. 1997;156:241-249.

171. Smith JP, Yelamarty RV, Kramer ST, et al. Effects of cholecystokinin on cytosolic calcium in pancreatic duct segments and ductal cells. Am J Physiol. 1993;264:G1177-G1183.

172. Stuenkel EL, Hootman SR. Secretagogue effects on intracellular calcium in pancreatic duct cells. Pflugers Arch. 1990;416:652-658.

173. Hasegawa H, Okabayashi Y, Koide M, et al. Effect of islet hormones on secretin-stimulated exocrine secretion in isolated perfused rat pancreas. Dig Dis Sci. 1993;38:1278-1283.

174. Berry SM, Fink AS. Insulin inhibits secretin-stimulated pancreatic bicarbonate output by a dose-dependent neurally mediated mechanism. Am J Physiol. 1996;270:G163-G170.

175. Howard-McNatt M, Simon T, Wang Y, et al. Insulin inhibits secretin-induced pancreatic bicarbonate output via cholinergic mechanisms. Pancreas. 2002;24:380-385.

176. Kim C, Kim K, Lee H, et al. Potentiation of cholecystokinin and secretin-induced pancreatic exocrine secretion by endogenous insulin in humans. Pancreas. 1999;18:410-414.

177. Lee KY, Zhou L, Ren XS, et al. An important role of endogenous insulin on exocrine pancreatic secretion in rats. Am J Physiol. 1990;258:G268-G274. 
178. Lee KY, Krusch D, Zhou L, et al. Effect of endogenous insulin on pancreatic exocrine secretion in perfused dog pancreas. Pancreas. 1995; 11:190-195.

179. Simon T, Marcus A, Royce CL, et al. Hyperglycemia alone does not inhibit secretin-induced pancreatic bicarbonate secretion. Pancreas. 2000;20:277-281.

180. Hegyi P, Rakonczay Z Jr. The inhibitory pathways of pancreatic ductal bicarbonate secretion. Int J Biochem Cell Biol. 2007;39:25-30.

181. Iwatsuki K, Yamagishi F, Chiba S. Effects of substance $P$ on pancreatic exocrine secretion stimulated by secretin, dopamine and cholecystokinin in dogs. Clin Exp Pharmacol Physiol. 1986;13:663-670.

182. Konturek SJ, Jaworek J, Tasler J, et al. Effect of substance P and its C-terminal hexapeptide on gastric and pancreatic secretion in the dog. Am J Physiol. 1981;241:G74-G81.

183. Katoh K, Murai K, Nonoyama T. Effects of substance $P$ on fluid and amylase secretion in exocrine pancreas of rat and mouse. Res Vet Sci. 1984;36:147-152.

184. Hegyi P, Gray MA, Argent BE. Substance P inhibits bicarbonate secretion from guinea pig pancreatic ducts by modulating an anion exchanger. Am J Physiol Cell Physiol. 2003;285:C268-C276.

185. Kemény LV, Hegyi P, Rakonczay Z Jr, et al. Substance P inhibits pancreatic ductal bicarbonate secretion via neurokinin receptors 2 and 3 in the guinea pig exocrine pancreas. Pancreas. 2011;40:793-795.

186. Hegyi P, Rakonczay Z Jr, Tiszlavicz L, et al. Protein kinase C mediates the inhibitory effect of substance $\mathrm{P}$ on $\mathrm{HCO}_{3}^{-}$secretion from guinea pig pancreatic ducts. Am J Physiol Cell Physiol. 2005;288: C1030-C1041.

187. Suzuki A, Naruse S, Kitagawa M, et al. 5-Hydroxytryptamine strongly inhibits fluid secretion in guinea pig pancreatic duct cells. J Clin Invest. 2001;108:749-756.

188. Beijer HJ, Maas AH, Charbon GA. A vasopressin-induced decrease in pancreatic blood flow and in pancreatic exocrine secretion in the anesthetized dog. Pflugers Arch. 1984;400:324-328.

189. Kitagawa M, Hayakawa T, Kondo T, et al. Plasma osmolality and exocrine pancreatic secretion. Int J Pancreatol. 1990;6:25-32.

190. Ko SB, Naruse S, Kitagawa M, et al. Arginine vasopressin inhibits fluid secretion in guinea pig pancreatic duct cells. Am J Physiol. 1999;277: G48-G54.

191. Brazeau P, Vale W, Burgus R, et al. Hypothalamic polypeptide that inhibits the secretion of immunoreactive pituitary growth hormone. Science. 1973;179:77-79.

192. Domschke S, Domschke W, Rosch W, et al. Inhibition by somatostatin of secretin-stimulated pancreatic secretion in man: a study with pure pancreatic juice. Scand J Gastroenterol. 1977;12:59-63.

193. Hanssen LE, Hanssen KF, Myren J. Inhibition of secretin release and pancreatic bicarbonate secretion by somatostatin infusion in man. Scand J Gastroenterol. 1977;12:391-394.

194. Wilson RM, Boden G, Shore LS, et al. Effect of somatostatin on meal-stimulated pancreatic exocrine secretions in dogs. Diabetes. 1977;26:7-10.

195. Konturek SJ, Cieszkowski M, Bilski J, et al. Effects of cyclic hexapeptide analog of somatostatin on pancreatic secretion in dogs. Proc Soc Exp Biol Med. 1985;178:68-72.

196. Susini C, Esteve JP, Vaysse N, et al. Somatostatin 28: effects on exocrine pancreatic secretion in conscious dogs. Gastroenterology. 1980;79: 720-724.

197. Kuvshinoff BW, Brodish RJ, James L, et al. Somatostatin inhibits secretin-induced canine pancreatic response via a cholinergic mechanism. Gastroenterology. 1993;105:539-547.

198. Hort Y, Baker E, Sutherland GR, et al. Gene duplication of the human peptide YY gene (PYY) generated the pancreatic polypeptide gene (PPY) on chromosome 17q21.1. Genomics. 1995;26:77-83.
199. Batterham RL, Le Roux CW, Cohen MA, et al. Pancreatic polypeptide reduces appetite and food intake in humans. J Clin Endocrinol Metab. 2003;88:3989-3992.

200. Lonovics J, Devitt P, Watson LC, et al. Pancreatic polypeptide. Arch Surg. 1981;116:1256-1264.

201. Konturek SJ, Meyers CA, Kwiecien N, et al. Effect of human pancreatic polypeptide and its C-terminal hexapeptide on pancreatic secretion in man and in the dog. Scand J Gastroenterol. 1982;17: 395-399.

202. Lonovics J, Guzman S, Devitt PG, et al. Action of pancreatic polypeptide on exocrine pancreas and on release of cholecystokinin and secretin. Endocrinology. 1981;108:1925-1930.

203. Taylor IL, Solomon TE, Walsh JH, et al. Pancreatic polypeptide. Metabolism and effect on pancreatic secretion in dogs. Gastroenterology. 1979;76:524-528.

204. Adrian TE, Ferri GL, Bacarese-Hamilton AJ, et al. Human distribution and release of a putative new gut hormone, peptide YY. Gastroenterology. 1985;89:1070-1077.

205. Liu CD, Aloia T, Adrian TE, et al. Peptide YY: a potential proabsorptive hormone for the treatment of malabsorptive disorders. Am Surg. 1996;62:232-236.

206. Pappas TN, Debas HT, Goto Y, et al. Peptide YY inhibits meal-stimulated pancreatic and gastric secretion. Am J Physiol. 1985;248:G118-G123.

207. Pappas TN, Debas HT, Taylor IL. Peptide YY: metabolism and effect on pancreatic secretion in dogs. Gastroenterology. 1985;89:1387-1392.

208. Masuda M, Tomita H, Okubo K, et al. Vagal efferent nerve-dependent inhibitory action of pancreatic polypeptide and peptide YY in conscious rats: comparison with somatostatin. J Auton Nerv Syst. 1994;50:131-138.

209. Arkosy P, Sapy P, Hauck M, et al. Effect of glucagon and somatostatin on pancreatic secretion in dogs. Acta Physiol Hung. 1996;84: 139-146.

210. Dyck WP, Rudick J, Hoexter B, et al. Influence of glucagon on pancreatic exocrine secretion. Gastroenterology. 1969;56:531-537.

211. Miller TA, Watson LC, Rayford PL, et al. The effect of glucagon on pancreatic secretion and plasma secretin in dogs. World J Surg. 1977;1:93-97.

212. Singer MV, Tiscornia OM, Mendes de Oliveiro JP, et al. Effect of glucagon on canine exocrine pancreatic secretion stimulated by a test meal. Can J Physiol Pharmacol. 1978;56:1-6.

213. Konturek SJ, Demitrescu T, Radecki T, et al. Effect of glucagon on gastric and pancreatic secretion and peptic ulcer formation in cats. Am J Dig Dis. 1974; 19:557-564.

214. Dyck WP, Texter EC Jr, Lasater JM, et al. Influence of glucagon on pancreatic exocrine secretion in man. Gastroenterology. 1970;58:532-539.

215. Harada H, Kochi F, Hanafusa E, et al. Studies on the effect of glucagon on human pancreatic secretion by analysis of endoscopically obtained pure pancreatic juice. Gastroenterol Jpn. 1985;20:28-36.

216. Kim E, Sheng M. PDZ domain proteins of synapses. Nat Rev Neurosci. 2004;5:771-781.

217. Gee HY, Park HW, Kim KH, et al. PDZ-based adaptor proteins in epithelial anion transport and VIP receptor regulation. $J$ Med Invest. 2009;56(suppl):302-305.

218. Hall RA, Premont RT, Chow CW, et al. The beta2-adrenergic receptor interacts with the $\mathrm{Na}^{+} / \mathrm{H}^{+}$-exchanger regulatory factor to control $\mathrm{Na}^{+} / \mathrm{H}^{+}$exchange. Nature. 1998;392:626-630.

219. Singh AK, Riederer B, Krabbenhoft A, et al. Differential roles of NHERF1, NHERF2, and PDZK1 in regulating CFTR-mediated intestinal anion secretion in mice. J Clin Invest. 2009;119: $540-550$. 
220. Rossmann H, Jacob P, Baisch S, et al. The CFTR associated protein CAP70 interacts with the apical $\mathrm{Cl}^{-} / \mathrm{HCO}_{3}^{-}$exchanger DRA in rabbit small intestinal mucosa. Biochemistry. 2005;44:4477-4487.

221. Blaine J, Weinman EJ, Cunningham R. The regulation of renal phosphate transport. Adv Chronic Kidney Dis. 2011;18:77-84.

222. Li M, Wang W, Soroka CJ, et al. NHERF-1 binds to Mrp2 and regulates hepatic Mrp2 expression and function. J Biol Chem. 2010;285: 19299-19307.

223. Kunkel MT, Garcia EL, Kajimoto T, et al. The protein scaffold NHERF-1 controls the amplitude and duration of localized protein kinase D activity. J Biol Chem. 2009;284:24653-24661.

224. Wheeler D, Sneddon WB, Wang B, et al. NHERF-1 and the cytoskeleton regulate the traffic and membrane dynamics of $\mathrm{G}$ protein-coupled receptors. J Biol Chem. 2007;282:25076-25087.

225. Pallagi P, Balla Z, Singh AK, et al. The role of pancreatic ductal secretion in protection against acute pancreatitis in mice. Crit Care Med. 2014;42:e177-e188.

226. Luo X, Choi JY, Ko SB, et al. $\mathrm{HCO}_{3}^{-}$-salvage mechanisms in the submandibular gland acinar and duct cells. J Biol Chem. 2001;276: 9808-9816.

227. Han W, Kim KH, Jo MJ, et al. Shank2 associates with and regulates $\mathrm{Na}^{+} / \mathrm{H}^{+}$exchanger 3. J Biol Chem. 2006;281:1461-1469.

228. Anselmo AN, Earnest S, Chen W, et al. WNK1 and OSR1 regulate the $\mathrm{Na}^{+}, \mathrm{K}^{+}, 2 \mathrm{Cl}^{-}$cotransporter in HeLa cells. Proc Natl Acad Sci U S A. 2006;103:10883-10888.

229. Kahle KT, Ring AM, Lifton RP. Molecular physiology of the WNK kinases. Annu Rev Physiol. 2008;70:329-355.

230. Richardson C, Alessi DR. The regulation of salt transport and blood pressure by the WNK-SPAK/OSR1 signalling pathway. J Cell Sci. 2008; 121:3293-3304.

231. Huang CL, Yang SS, Lin SH. Mechanism of regulation of renal ion transport by WNK kinases. Curr Opin Nephrol Hypertens. 2008;17: 519-525.

232. McCormick JA, Ellison DH. The WNKs: atypical protein kinases with pleiotropic actions. Physiol Rev. 2011;91:177-219.

233. Vitari AC, Deak M, Morrice NA, et al. The WNK1 and WNK4 protein kinases that are mutated in Gordon's hypertension syndrome phosphorylate and activate SPAK and OSR 1 protein kinases. Biochem J. 2005;391:17-24.

234. He G, Wang HR, Huang SK, et al. Intersectin links WNK kinases to endocytosis of ROMK1. J Clin Invest. 2007;117:1078-1087.

235. Yang D, Li Q, So I, et al. IRBIT governs epithelial secretion in mice by antagonizing the WNK/SPAK kinase pathway. $J$ Clin Invest. 2011;121: 956-965.

236. Kahle KT, Wilson FH, Lalioti M, et al. WNK kinases: molecular regulators of integrated epithelial ion transport. Curr Opin Nephrol Hypertens. 2004;13:557-562.

237. Ando H, Mizutani A, Matsu-ura T, et al. IRBIT, a novel inositol 1,4,5-trisphosphate (IP3) receptor-binding protein, is released from the IP3 receptor upon IP3 binding to the receptor. J Biol Chem. 2003;278: 10602-10612.

238. Ando H, Mizutani A, Kiefer H, et al. IRBIT suppresses IP3 receptor activity by competing with IP3 for the common binding site on the IP3 receptor. Mol Cell. 2006;22:795-806.

239. Devogelaere B, Nadif Kasri N, Derua R, et al. Binding of IRBIT to the IP3 receptor: determinants and functional effects. Biochem Biophys Res Commun. 2006;343:49-56.

240. He P, Zhang H, Yun CC. IRBIT, inositol 1,4,5-triphosphate (IP3) receptor-binding protein released with IP3, binds $\mathrm{Na}^{+} / \mathrm{H}^{+}$exchanger NHE3 and activates NHE3 activity in response to calcium. $J$ Biol Chem. 2008:283:33544-33553.
241. Yang D, Shcheynikov N, Muallem S. IRBIT: it is everywhere. Neurochem Res. 2011;36:1166-1174.

242. Wang Y, Wrennall JA, Cai Z, et al. Understanding how cystic fibrosis mutations disrupt CFTR function: from single molecules to animal models. Int J Biochem Cell Biol. 2014;52:47-57.

243. Boucher RC. New concepts of the pathogenesis of cystic fibrosis lung disease. Eur Respir J. 2004;23:146-158.

244. Welch WJ. Role of quality control pathways in human diseases involving protein misfolding. Semin Cell Dev Biol. 2004;15:31-38.

245. Wang X, Kim J, McWilliams R, et al. Increased prevalence of chronic rhinosinusitis in carriers of a cystic fibrosis mutation. Arch Otolaryngol Head Neck Surg. 2005;131:237-240.

246. Haack A, Aragao GG, Novaes MR. Pathophysiology of cystic fibrosis and drugs used in associated digestive tract diseases. World J Gastroenterol. 2013;19:8552-8561

247. Lubamba B, Dhooghe B, Noel S, et al. Cystic fibrosis: insight into CFTR pathophysiology and pharmacotherapy. Clin Biochem. 2012;45: 1132-1144.

248. Andersen DH. Cystic fibrosis of the pancreas and its relation to celiac disease: a clinical and pathological study. Am J Dis Child. 1938; 344-399.

249. Ahmed N, Corey M, Forstner G, et al. Molecular consequences of cystic fibrosis transmembrane regulator (CFTR) gene mutations in the exocrine pancreas. Gut. 2003;52:1159-1164.

250. Steward MC, Ishiguro H. Molecular and cellular regulation of pancreatic duct cell function. Curr Opin Gastroenterol. 2009;25:447-453.

251. Galietta LJ. Managing the underlying cause of cystic fibrosis: a future role for potentiators and correctors. Paediatr Drugs. 2013;15:393-402.

252. Rowe SM, Verkman AS. Cystic fibrosis transmembrane regulator correctors and potentiators. Cold Spring Harb Perspect Med. 2013; 3:a009761.

253. Griffin MA, Restrepo MS, Abu-El-Haija M, et al. A novel gene delivery method transduces porcine pancreatic duct epithelial cells. Gene Ther. 2014;21:123-130

254. Fisher JT, Zhang Y, Engelhardt JF. Comparative biology of cystic fibrosis animal models. Methods Mol Biol. 2011;742:311-334.

255. Guilbault C, Saeed Z, Downey GP, et al. Cystic fibrosis mouse models. Am J Respir Cell Mol Biol. 2007;36:1-7.

256. Egan ME. How useful are CF mouse models? Drug Discov Today Dis Models. 2009;6:35-41.

257. Winpenny JP, Harris A, Hollingsworth MA, et al. Calcium-activated chloride conductance in a pancreatic adenocarcinoma cell line of ductal origin (HPAF) and in freshly isolated human pancreatic duct cells. Pflugers Arch. 1998;435:796-803.

258. Pascua P, Garcia M, Fernandez-Salazar MP, et al. Ducts isolated from the pancreas of CFTR-null mice secrete fluid. Pflugers Arch. 2009;459: 203-214.

259. Rogers CS, Stoltz DA, Meyerholz DK, et al. Disruption of the CFTR gene produces a model of cystic fibrosis in newborn pigs. Science. 2008;321:1837-1841

260. Sun X, Sui H, Fisher JT, et al. Disease phenotype of a ferret CFTR-knockout model of cystic fibrosis. J Clin Invest. 2010;120 3149-3160.

261. Uc A, Giriyappa R, Meyerholz DK, et al. Pancreatic and biliary secretion are both altered in cystic fibrosis pigs. Am J Physiol Gastrointest Liver Physiol. 2012;303:G961-G968.

262. Abu-El-Haija M, Ramachandran S, Meyerholz DK, et al. Pancreatic damage in fetal and newborn cystic fibrosis pigs involves the activation of inflammatory and remodeling pathways. Am J Pathol. 2012;181: 499-507. 
263. Sun X, Olivier AK, Yi Y, et al. Gastrointestinal pathology in juvenile and adult CFTR-knockout ferrets. Am J Pathol. 2014;184: 1309-1322.

264. Augarten A, Ben Tov A, Madgar I, et al. The changing face of the exocrine pancreas in cystic fibrosis: the correlation between pancreatic status, pancreatitis and cystic fibrosis genotype. Eur J Gastroenterol Hepatol. 2008;20:164-168.

265. Ooi CY, Dorfman R, Cipolli M, et al. Type of CFTR mutation determines risk of pancreatitis in patients with cystic fibrosis. Gastroenterology. 2011;140:153-161.

266. Mankad P, James A, Siriwardena AK, et al. Insulin protects pancreatic acinar cells from cytosolic calcium overload and inhibition of plasma membrane calcium pump. J Biol Chem. 2012;287:1823-1836.

267. Pandol SJ, Raraty M. Pathobiology of alcoholic pancreatitis. Pancreatology. 2007; 7:105-114.

268. Petersen $\mathrm{OH}$, Tepikin AV, Gerasimenko JV, et al. Fatty acids, alcohol and fatty acid ethyl esters: toxic $\mathrm{Ca}^{2+}$ signal generation and pancreatitis. Cell Calcium. 2009;45:634-642.

269. Banks PA, Bollen TL, Dervenis C, et al. Classification of acute pancreatitis - 2012: revision of the Atlanta classification and definitions by international consensus. Gut. 2013;62:102-111.

270. Hegyi P, Perides G, Steer ML, et al. Commonly employed rodent models of experimental acute pancreatitis: their strengths and weaknesses, relevance to human disease, selection, and appropriate use. The Pancreapedia: Exocrine Pancreas Knowledge Base. 2013. Available at: http://www.pancreapedia.org/reviews/commonly-employed-rodentmodels-of-experimental-acute-pancreatitis-their-strengths-and-weakn. Accessed August 20, 2015.

271. Saluja AK, Lerch MM, Phillips PA, et al. Why does pancreatic overstimulation cause pancreatitis? Annu Rev Physiol. 2007; 69:249-269.

272. Rakonczay Z Jr, Hegyi P, Takacs T, et al. The role of NF-kappaB activation in the pathogenesis of acute pancreatitis. Gut. 2008;57: 259-267.

273. Maleth J, Venglovecz V, Razga Z, et al. Non-conjugated chenodeoxycholate induces severe mitochondrial damage and inhibits bicarbonate transport in pancreatic duct cells. Gut. 2011;60:136-138.

274. Venglovecz V, Rakonczay Z Jr, Ozsvari B, et al. Effects of bile acids on pancreatic ductal bicarbonate secretion in guinea pig. Gut. 2008;57: 1102-1112.

275. Yamamoto A, Ishiguro H, Ko SB, et al. Ethanol induces fluid hypersecretion from guinea-pig pancreatic duct cells. J Physiol. 2003;551: 917-926.

276. Ignath I, Hegyi P, Venglovecz V, et al. CFTR expression but not $\mathrm{Cl}^{-}$transport is involved in the stimulatory effect of bile acids on apical $\mathrm{Cl}^{-} / \mathrm{HCO}_{3}^{-}$exchange activity in human pancreatic duct cells. Pancreas. 2009;38:921-929.

277. Maleth J, Rakonczay Z Jr, Venglovecz V, et al. Central role of mitochondrial injury in the pathogenesis of acute pancreatitis Acta Physiol (Oxf). 2013;207:226-235.

278. Takacs T, Rosztoczy A, Maleth J, et al. Intraductal acidosis in acute biliary pancreatitis. Pancreatology. 2013;13:333-335.

279. Apte MV, Pirola RC, Wilson JS. Fatty acid ethyl esters - alcohol's henchmen in the pancreas? Gastroenterology. 2006;130:992-995.

280. Petersen $\mathrm{OH}$, Sutton R. $\mathrm{Ca}^{2+}$ signalling and pancreatitis: effects of alcohol, bile and coffee. Trends Pharmacol Sci. 2006;27:113-120.

281. Criddle DN, Murphy J, Fistetto G, et al. Fatty acid ethyl esters cause pancreatic calcium toxicity via inositol trisphosphate receptors and loss of ATP synthesis. Gastroenterology. 2006;130:781-793.

282. Criddle DN, Raraty MG, Neoptolemos JP, et al. Ethanol toxicity in pancreatic acinar cells: mediation by nonoxidative fatty acid metabolites. Proc Natl Acad Sci U S A. 2004;101:10738-10743.
283. Gerasimenko JV, Lur G, Sherwood MW, et al. Pancreatic protease activation by alcohol metabolite depends on $\mathrm{Ca}^{2+}$ release via acid store $\mathrm{IP}_{3}$ receptors. Proc Natl Acad Sci U S A. 2009;106:10758-10763.

284. Judak L, Hegyi P, Rakonczay Z Jr, et al. Ethanol and its non-oxidative metabolites profoundly inhibit CFTR function in pancreatic epithelial cells which is prevented by ATP supplementation. Pflugers Arch. 2014, 466:549-562.

285. Lerch MM, Gorelick FS. Early trypsinogen activation in acute pancreatitis. Med Clin North Am. 2000;84:549-563, viii.

286. Thrower EC, Gorelick FS, Husain SZ. Molecular and cellular mechanisms of pancreatic injury. Curr Opin Gastroenterol. 2010;26: 484-489.

287. Geokas MC, Rinderknecht H. Free proteolytic enzymes in pancreatic juice of patients with acute pancreatitis. Am J Dig Dis. 1974;19: 591-598.

288. Renner IG, Rinderknecht H, Douglas AP. Profiles of pure pancreatic secretions in patients with acute pancreatitis: the possible role of proteolytic enzymes in pathogenesis. Gastroenterology. 1978;75: 1090-1098.

289. Kawabata A, Kuroda R, Nishida M, et al. Protease-activated receptor-2 (PAR-2) in the pancreas and parotid gland: immunolocalization and involvement of nitric oxide in the evoked amylase secretion. Life Sci. 2002;71:2435-2446.

290. Singh VP, Bhagat L, Navina S, et al. Protease-activated receptor-2 protects against pancreatitis by stimulating exocrine secretion. Gut. 2007;56: 958-964.

291. Nguyen TD, Moody MW, Steinhoff M, et al. Trypsin activates pancreatic duct epithelial cell ion channels through proteinase-activated receptor-2. J Clin Invest. 1999;103:261-269.

292. Alvarez C, Regan JP, Merianos D, et al. Protease-activated receptor-2 regulates bicarbonate secretion by pancreatic duct cells in vitro. Surgery. 2004;136:669-676.

293. Pallagi P, Venglovecz V, Rakonczay Z Jr, et al. Trypsin reduces pancreatic ductal bicarbonate secretion by inhibiting CFTR $\mathrm{Cl}^{-}$channels and luminal anion exchangers. Gastroenterology. 2011;141:2228-2239.e1-6.

294. Kawabata A, Matsunami M, Tsutsumi M, et al. Suppression of pancreatitis-related allodynia/hyperalgesia by proteinase-activated receptor-2 in mice. Br J Pharmacol. 2006;148:54-60.

295. Laukkarinen JM, Weiss ER, van Acker GJ, et al. Protease-activated receptor-2 exerts contrasting model-specific effects on acute experimental pancreatitis. J Biol Chem. 2008;283:20703-20712.

296. Sharma A, Tao X, Gopal A, et al. Protection against acute pancreatitis by activation of protease-activated receptor-2. Am J Physiol Gastrointest Liver Physiol. 2005;288:G388-G395.

297. Namkung W, Han W, Luo X, et al. Protease-activated receptor 2 exerts local protection and mediates some systemic complications in acute pancreatitis. Gastroenterology. 2004;126:1844-1859.

298. Namkung W, Yoon JS, Kim KH, et al. PAR2 exerts local protection against acute pancreatitis via modulation of MAP kinase and MAP kinase phosphatase signaling. Am J Physiol Gastrointest Liver Physiol. 2008; 295:G886-G894.

299. Michael ES, Kuliopulos A, Covic L, et al. Pharmacological inhibition of PAR2 with the pepducin P2pal-18S protects mice against acute experimental biliary pancreatitis. Am J Physiol Gastrointest Liver Physiol. 2013;304:G516-G526.

300. Sadr-Azodi O, Andren-Sandberg A, Orsini N, et al. Cigarette smoking, smoking cessation and acute pancreatitis: a prospective population-based study. Gut. 2012;61:262-267.

301. Rab A, Rowe SM, Raju SV, et al. Cigarette smoke and CFTR: implications in the pathogenesis of COPD. Am J Physiol Lung Cell Mol Physiol. 2013;305:L530-L541. 
302. Raju SV, Jackson PL, Courville CA, et al. Cigarette smoke induces systemic defects in cystic fibrosis transmembrane conductance regulator function. Am J Respir Crit Care Med. 2013;188:1321-1330.

303. Rasmussen JE, Sheridan JT, Polk W, et al. Cigarette smoke-induced $\mathrm{Ca}^{2+}$ release leads to cystic fibrosis transmembrane conductance regulator (CFTR) dysfunction. J Biol Chem. 2014;289:7671-7681.

304. Clunes LA, Davies CM, Coakley RD, et al. Cigarette smoke exposure induces CFTR internalization and insolubility, leading to airway surface liquid dehydration. FASEB J. 2012;26:533-545.

305. Konturek SJ, Dale J, Jacobson ED, et al. Mechanisms of nicotine-induced inhibition of pancreatic secretion of bicarbonate in the dog. Gastroenterology. 1972;62:425-429.

306. Boden G, Shore LS, Essa-Koumar N, et al. Effect of nicotine on serum secretin and exocrine pancreatic secretion. Am J Dig Dis. 1976;21: 974-977.

307. DiMagno MJ, DiMagno EP. Pancreas divisum does not cause pancreatitis, but associates with CFTR mutations. Am J Gastroenterol. 2012;107: 318-320.

308. DiMagno MJ, Lee SH, Hao Y, et al. A proinflammatory, antiapoptotic phenotype underlies the susceptibility to acute pancreatitis in cystic fibrosis transmembrane regulator (-/-) mice. Gastroenterology. 2005; 129:665-681.

309. Cavestro GM, Zuppardo RA, Bertolini S, et al. Connections between genetics and clinical data: role of MCP-1, CFTR, and SPINK-1 in the setting of acute, acute recurrent, and chronic pancreatitis. Am J Gastroenterol. 2010;105:199-206.

310. Hegyi P, Rakonczay Z. Insufficiency of electrolyte and fluid secretion by pancreatic ductal cells leads to increased patient risk for pancreatitis. Am J Gastroenterol. 2010;105:2119-2120.

311. Kloppel G, Maillet B. Chronic pancreatitis: evolution of the disease. Hepatogastroenterology. 1991;38:408-412.

312. Kloppel G, Maillet B. The morphological basis for the evolution of acute pancreatitis into chronic pancreatitis. Virchows Arch A Pathol Anat Histopathol. 1992;420:1-4.

313. Braganza JM, Lee SH, McCloy RF, et al. Chronic pancreatitis. Lancet. 2011;377:1184-1197.

314. Sasikala M, Talukdar R, Pavan Kumar P, et al. beta-Cell dysfunction in chronic pancreatitis. Dig Dis Sci. 2012;57:1764-1772.

315. Malka D, Hammel P, Maire F, et al. Risk of pancreatic adenocarcinoma in chronic pancreatitis. Gut. 2002;51:849-852.

316. Lowenfels AB, Maisonneuve P, Cavallini G, et al. Prognosis of chronic pancreatitis: an international multicenter study. International Pancreatitis Study Group. Am J Gastroenterol. 1994;89: 1467-1471.

317. Maisonneuve P, Lowenfels AB, Mullhaupt B, et al. Cigarette smoking accelerates progression of alcoholic chronic pancreatitis. Gut. 2005;54:510-514.

318. Kadiyala V, Lee LS, Banks PA, et al. Cigarette smoking impairs pancreatic duct cell bicarbonate secretion. JOP. 2013;14:31-38.

319. Dominguez Munoz JE. Diagnosis of chronic pancreatitis: functional testing. Best Pract Res Clin Gastroenterol. 2010;24 233-241.

320. Lindkvist B. Diagnosis and treatment of pancreatic exocrine insufficiency. World J Gastroenterol. 2013;19:7258-7266.

321. Griffin N, Charles-Edwards G, Grant LA. Magnetic resonance cholangiopancreatography: the ABC of MRCP. Insights Imaging. 2012;3:11-21.

322. Sherman S, Freeman ML, Tarnasky PR, et al. Secretin (RG1068) administration increases sensitivity of detection of duct abnormalities by magnetic resonance cholangiopancreatography in patients with pancreatitis. Gastroenterology. 2014;147:646-654.
323. Tirkes T, Menias CO, Sandrasegaran K. MR imaging techniques for pancreas. Radiol Clin North Am. 2012;50:379-393.

324. Sanyal R, Stevens T, Novak E, et al. Secretin-enhanced MRCP: review of technique and application with proposal for quantification of exocrine function. AJR Am J Roentgenol. 2012;198: $124-132$.

325. Kamisawa T, Chari ST, Lerch MM, et al. Recent advances in autoimmune pancreatitis: type 1 and type 2. Gut. 2013;62:1373-1380.

326. Rakonczay Z Jr, Vag J, Foldes A, et al. Chronic inflammation in the pancreas and salivary glands - lessons from similarities and differences in pathophysiology and treatment modalities. Curr Pharm Des. 2014;20:1104-1120.

327. Ito T, Kawabe K, Arita Y, et al. Evaluation of pancreatic endocrine and exocrine function in patients with autoimmune pancreatitis. Pancreas. 2007;34:254-259.

328. Ko SB, Mizuno N, Yatabe Y, et al. Corticosteroids correct aberrant CFTR localization in the duct and regenerate acinar cells in autoimmune pancreatitis. Gastroenterology. 2010;138:1988-1996.

329. Ko SB, Azuma S, Yoshikawa T, et al. Molecular mechanisms of pancreatic stone formation in chronic pancreatitis. Front Physiol. 2012;3:415

330. Felderbauer P, Klein W, Bulut K, et al. Mutations in the calcium-sensing receptor: a new genetic risk factor for chronic pancreatitis? Scand J Gastroenterol. 2006;41:343-348.

331. Muddana V, Lamb J, Greer JB, et al. Association between calcium sensing receptor gene polymorphisms and chronic pancreatitis in a US population: role of serine protease inhibitor Kazal 1type and alcohol. World $J$ Gastroenterol. 2008;14:4486-4491.

332. Choudari CP, Imperiale TF, Sherman S, et al. Risk of pancreatitis with mutation of the cystic fibrosis gene. Am J Gastroenterol. 2004;99: $1358-1363$

333. Whitcomb DC. Genetic risk factors for pancreatic disorders. Gastroenterology. 2013;144:1292-1302.

334. Cohn JA, Friedman KJ, Noone PG, et al. Relation between mutations of the cystic fibrosis gene and idiopathic pancreatitis. N Engl J Med. 1998; 339:653-658

335. Sharer N, Schwarz M, Malone G, et al. Mutations of the cystic fibrosis gene in patients with chronic pancreatitis. N Engl J Med. 1998;339: 645-652.

336. Larusch J, Whitcomb DC. Genetics of pancreatitis with a focus on the pancreatic ducts. Minerva Gastroenterol Dietol. 2012;58:299-308

337. Schneider A, Larusch J, Sun X, et al. Combined bicarbonate conductance-impairing variants in CFTR and SPINK1 variants are associated with chronic pancreatitis in patients without cystic fibrosis. Gastroenterology. 2011;140:162-171.

338. Czako L, Hegyi P, Rakonczay Z Jr, et al. Interactions between the endocrine and exocrine pancreas and their clinical relevance. Pancreatology. 2009;9:351-359.

339. Hardt PD, Ewald N. Exocrine pancreatic insufficiency in diabetes mellitus: a complication of diabetic neuropathy or a different type of diabetes? Exp Diabetes Res. 2011;2011:761950.

340. Frier BM, Saunders JH, Wormsley KG, et al. Exocrine pancreatic function in juvenile-onset diabetes mellitus. Gut. 1976;17: 685-691.

341. Lankisch PG, Manthey G, Otto J, et al. Exocrine pancreatic function in insulin-dependent diabetes mellitus. Digestion. 1982;25: 211-216.

342. Kim KH, Lee HS, Kim CD, et al. Evaluation of pancreatic exocrine function using pure pancreatic juice in noninsulin-dependent diabetes mellitus. J Clin Gastroenterol. 2000;31:51-54. 
343. el Newihi H, Dooley CP, Saad C, et al. Impaired exocrine pancreatic function in diabetics with diarrhea and peripheral neuropathy. Dig Dis $\mathrm{Sci}$. 1988;33:705-710

344. Hardt PD, Hauenschild A, Nalop J, et al. High prevalence of exocrine pancreatic insufficiency in diabetes mellitus. A multicenter study screening fecal elastase 1 concentrations in 1,021 diabetic patients. Pancreatology. 2003;3:395-402.

345. Keller J, Layer P. Human pancreatic exocrine response to nutrients in health and disease. Gut. 2005;54(suppl 6):vi1-vi28.

346. Hardt PD, Killinger A, Nalop J, et al. Chronic pancreatitis and diabetes mellitus. A retrospective analysis of 156 ERCP investigations in patients with insulin-dependent and non-insulin-dependent diabetes mellitus. Pancreatology. 2002;2:30-33.
347. Nakanishi K, Kobayashi T, Miyashita H, et al. Exocrine pancreatic ductograms in insulin-dependent diabetes mellitus. Am J Gastroenterol. 1994;89:762-766.

348. Futakuchi S, Ishiguro $\mathrm{H}$, Naruse $\mathrm{S}$, et al. High glucose inhibits $\mathrm{HCO}_{3}^{-}$and fluid secretion in rat pancreatic ducts. Pflugers Arch. 2009;459:215-226.

349. Hootman SR, Jones JE, Kapoor R, et al. Sodium, potassium-activated adenosine triphosphatase activity is impaired in the guinea pig pancreatic duct system in streptozotocin-induced diabetes. Biochem Biophys Res Commun. 1998;243:869-873.

350. Fluhr G, Mayerle J, Weber E, et al. Pre-study protocol MagPEP: a multicentre randomized controlled trial of magnesium sulphate in the prevention of post-ERCP pancreatitis. BMC Gastroenterol. 2013; $13: 11$ 